\title{
O-Methylation in Carbohydrates: An NMR and MD Simulation Study with Application to Methylcellulose
}

\author{
Alessandro Ruda, Göran Widmalm,* and Jakob Wohlert* \\ Cite This: J. Phys. Chem. B 2021, 125, 11967-11979 \\ Read Online
}

ABSTRACT: Methylated carbohydrates are important from both biological and technical perspectives. Specifically, methylcellulose is an interesting cellulose derivative that has applications in foods, materials, cosmetics, and many other fields. While the molecular dynamics simulation technique has the potential for both advancing the fundamental understanding of this polymer and aiding in the development of specific applications, a general drawback is the lack of experimentally validated interaction potentials for the methylated moieties. In the present study, simulations using the GROMOS 56 carbohydrate force field are compared to NMR spin-spin coupling constants related to the conformation of the exocyclic torsion angle $\omega$ in D-

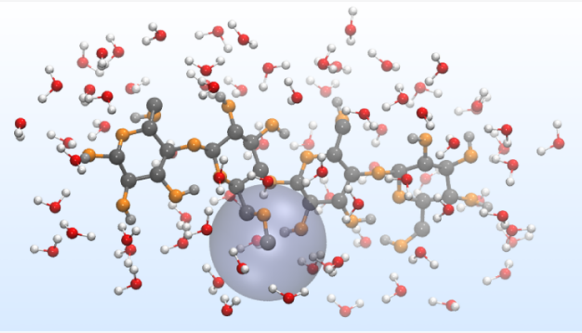
glucopyranose and derivatives containing a 6-O-methyl substituent and a ${ }^{13} \mathrm{C}$-isotopologue thereof. A ${ }^{3} J_{\mathrm{CC}}$ Karplus-type relationship is proposed for the $\mathrm{C} 5-\mathrm{C} 6-\mathrm{O} 6-\mathrm{C}_{\mathrm{Me}}$ torsion angle. Moreover, solvation free energies are compared to experimental data for small model compounds. Alkylation in the form of 6-O-methylation affects exocyclic torsion only marginally. Computed solvation free energies between nonmethylated and methylated molecules were internally consistent, which validates the application of these interaction potentials for more specialized purposes.

\section{INTRODUCTION}

Methylation in carbohydrates is found in many places in nature such as bacteria, fungi, worms, mollusks, algae, and plants, but it is still rare compared to other modifications. ${ }^{1}$ Methylated oligosaccharides are only found in bacteria and plants, where for instance certain plant hemicelluloses (xylans) are rich in 4O-methylated glucuronic acids, ${ }^{2}$ and 6-O-methyl substitutions are present in glucosyl residues from mycobacterial polysaccharides $^{3-6}$ and in a polysaccharide from the leaves of the plant Catharanthus rosea.

Much is still not known about the specific function of methylation in living organisms, although it seems to be connected to molecular recognition. ${ }^{1}$ In addition, it also provides variation in chemical properties by rendering the carbohydrate more hydrophobic, and also by modulating the conformational space. ${ }^{8}$ This is exploited in methylcellulose (MC) which is synthesized from cellulose by O-methylation in positions 2, 3, and/or 6 of the glucose units (Figure 1a). Being a cellulose derivative, MC belongs to an important class of biopolymers that are renewable, nontoxic, easy to synthesize, cheap, industrially viable, and in most cases water-soluble (in contrast to cellulose) with an interesting phase behavior. Thus, MC is used in foods, cosmetics, pharmaceutics, construction materials, adhesives, drilling fluids, and so forth. ${ }^{9}$ As a consequence of the synthesis route, commercial MCs are characterized by a heterogeneous distribution of methyl groups along the polymer chain, while homogeneous methylation can also be achieved through dissolution prior to the methylation reaction.
Despite often being described as a hydrophilic polymer, cellulose is completely insoluble in water, where it forms crystalline aggregates that are characterized by an extensive hydrogen bond network. However, as these internal hydrogen bonds are of comparable energy as potential hydrogen bonds with water molecules, hydrogen bonding is not the thermodynamic driving force for cellulose aggregation. Instead, the free energy is dominated by the large penalty of hydrating the pseudo-flat apolar surfaces of the glucose rings, a.k.a. the hydrophobic effect. ${ }^{10,11} \mathrm{O}$-methylation disrupts the hydrogen bond network that allows for close packing of the glucan chains and tips the energy balance in favor of dissolution. However, if the methylation is driven too far, hydrophobic effects again start to dominate, and the MC polymer becomes insoluble. Depending on the synthesis route, MCs with a degree of substitution (DS) between 0.9 and 2.5 are water-soluble at room temperature and below. ${ }^{9}$ However, if the temperature increases above a lower critical solution temperature of $303 \mathrm{~K}$, MC chains start to associate, and above approximately $323 \mathrm{~K}$, phase separation starts to occur, eventually leading to gel formation. ${ }^{12,13}$ Several mechanisms for the thermal behavior of

Received: August 17, 2021

Revised: October 7, 2021

Published: October 27, 2021 

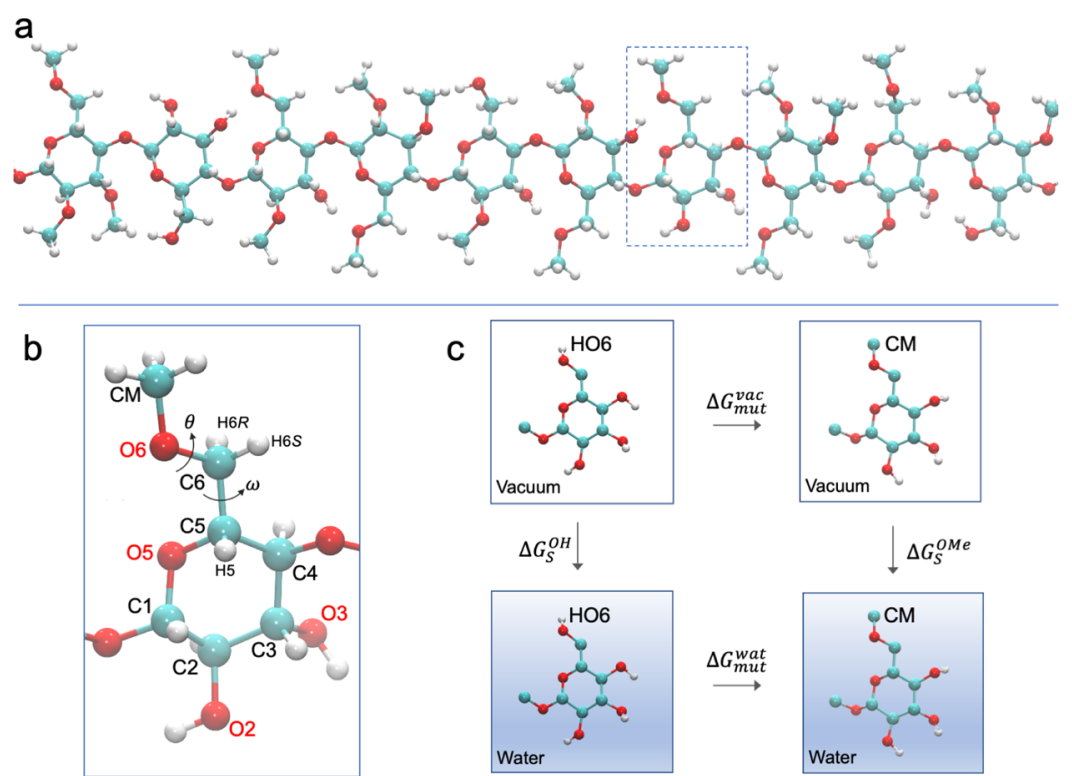

C
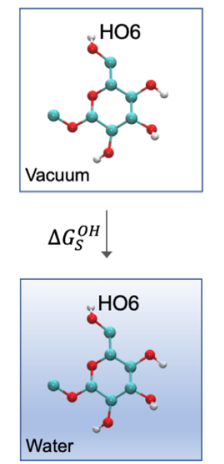
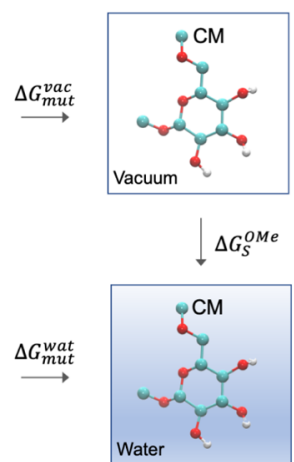

Figure 1. (a) Illustration of a MC chain in an all-atom representation which is randomly 2-, 3-, and 6-O-methylated. (b) Close-up of a 6-Omethylated glucopyranose unit with the notations for atoms and torsion angles used in this article. (c) Thermodynamic cycle with the arrows defining the sign of the corresponding free energy change. Vertical paths represent solvation free energies and horizontal paths represent the mutation of $\beta$-D-Glcp-OMe into $\beta$-D-Glcp6Me-OMe, respectively. Note that the monosaccharides are drawn in the GROMOS united atoms representation (i.e. without explicit aliphatic hydrogen atoms), which is used in the simulations.

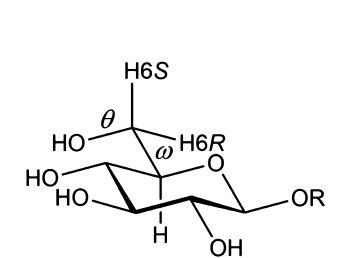

$1 \mathrm{R}=\mathrm{H} ; 2 \mathrm{R}=\mathrm{Me}$
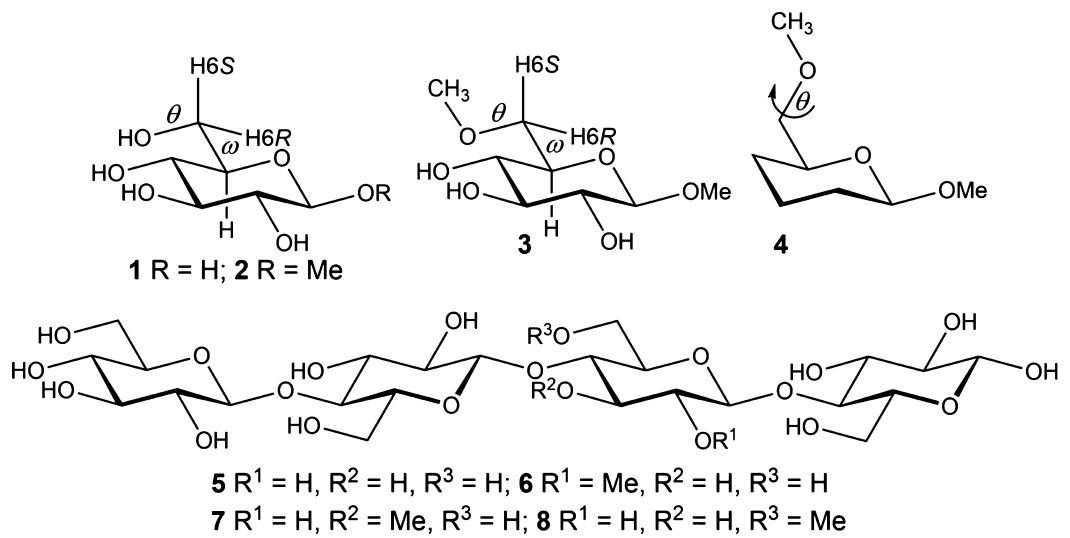

Figure 2. Schematic representation of model substances: (top) $\beta$-D-Glcp (1) or $\beta$-D-Glcp-OMe (2), $\beta$-D-Glcp6Me-OMe (3), (2R,6S)-2-methoxy-6(methoxymethyl)tetrahydro-2H-pyran (4), (bottom) $\beta$-cellotetraose (5), and $\beta$-cellotetraose O-methylated in the C2, C3, or C6 position (6-8). The exo-cyclic torsion angles $\omega$ and $\theta$ are indicated. Hydroxymethyl protons $\mathrm{H} 6_{\text {pro- } R}$ and $H 6_{\text {pro- } S}$ are denoted by H6R and $\mathrm{H} 6 S$, respectively.

MC have been proposed, so far without a clear consensus having been reached. Most of them invoke the heterogeneous distribution of methyl groups as a key factor, which leads to the formation of network junctions between highly methylated sections as a result of hydrophobic association at elevated temperatures, ${ }^{12}$ and indeed, homogenously methylated cellulose does not exhibit the sol-gel transition. ${ }^{14}$

Solution state NMR is an invaluable tool for studying molecular structure of glycans, ${ }^{15,16}$ for instance, through the assignment of population-averaged rotational states from spin-spin couplings using Karplus-type relationships. ${ }^{17}$ While numerous Karplus equations for monosaccharides and their derivatives have been published, an appropriate equation for the $\theta$ torsion angle (Figure $1 \mathrm{~b}$ ) for 6-O-methylated compounds is missing. In addition, molecular dynamics (MD) simulation has evolved into an important tool for studying physical properties of biomolecules, especially in combination with experimental methods, such as NMR spectroscopy. Several of the most-used force fields for MD simulation of carbohydrates, such as CHARMM, ${ }^{18}$ GLY$\mathrm{CAM},{ }^{19}$ and GROMOS, ${ }^{20}$ provide patches or general rules for the inclusion of common derivatizations, including methylation. However, such modifications were not specifically targeted in the force field optimization, and have thus not, from what it appears, been as extensively validated as the unsubstituted sugars. Nevertheless, MD has been used to study methylated carbohydrates and carbohydrate polymers in solution, although reports on simulations of MC are scarce. Most notably, Larson et al. have used both atomistic and coarse-grained $\mathrm{MD}$ to study the phase behavior of $\mathrm{MC},{ }^{21-23}$ and $\mathrm{Yu}$ et al. studied the effect of $\mathrm{O}$-methylation in cellooligomers $^{24}$ on both structure and solvation properties, while Delbianco and co-workers ${ }^{25}$ studied conformational properties systematically with respect to various modifications, including O-methylation. 
In this work, the solution structure of 6-O-methylated glucopyranosides is investigated by NMR and MD simulations. A new ${ }^{3} J_{\mathrm{CC}}$ Karplus-type relation for the exo-cyclic $\theta$ torsion is parameterized. This equation is used to validate simulations using the GROMOS carbohydrate force field. ${ }^{20}$ Simulations are further extended to include selectively methylated cellooligomers with the purpose of studying the effect on the free energy of hydration. These results are compared to experimental data for methylated model compounds in solution.

\section{METHODS}

Saccharides. The carbohydrate model compounds used were the three monosaccharides $\beta$-D-Glcp, $\beta$-D-Glcp-OMe and $\beta$-D-Glcp6Me-OMe, and cellotetraose, which was selectively 2-, 3-, or 6-O-methylated (Figure 2). The synthesis of the compounds used in NMR experiments is described in Supporting Information.

NMR Spectroscopy. NMR experiments for conformational analysis utilized monosaccharides dissolved in $\mathrm{D}_{2} \mathrm{O}$ (99.96\%) at a concentration of 30-40 mM. The NMR spectra were recorded on Bruker spectrometers, viz., an AVANCE III $700 \mathrm{MHz}$ equipped with a $5 \mathrm{~mm}$ TCI Z-Gradient Cryoprobe $\left({ }^{1} \mathrm{H} /{ }^{13} \mathrm{C} /{ }^{15} \mathrm{~N}\right)$ or an AVANCE III $600 \mathrm{MHz}$ equipped with a 5 mm TXI inverse Z-Gradient ${ }^{1} \mathrm{H} /{ }^{13} \mathrm{C} /{ }^{31} \mathrm{P}$ probe. The chemical shifts were referenced to internal sodium 3-trimethylsilyl$\left(2,2,3,3-{ }^{2} \mathrm{H}_{4}\right)$-propanoate (TSP) in $\mathrm{D}_{2} \mathrm{O}\left(\delta_{\mathrm{H}} 0.0\right)$ and external $10 \%$ 1,4-dioxane in $\mathrm{D}_{2} \mathrm{O}\left(\delta_{\mathrm{C}} 67.4\right) .{ }^{1} \mathrm{H}$ and ${ }^{13} \mathrm{C} \mathrm{NMR}$ experiments were recorded at $298 \mathrm{~K}$, unless otherwise stated, with a digital resolution of 0.2 and $0.5 \mathrm{~Hz}$ /point, respectively, and zero-filled prior to Fourier transformation of the FIDs. ${ }^{n} J_{\mathrm{HH}}$ and ${ }^{3} J_{\mathrm{CH}}$ coupling constants were extracted by lineshape analysis using the NMR spin-simulation software PERCH; ${ }^{26}$ the experimental error for ${ }^{n} J_{\mathrm{HH}}$ is estimated to be $\leq 0.2 \mathrm{~Hz}$. The homonuclear broadband-decoupled pure shift ${ }^{1} \mathrm{H}$ NMR spectrum $^{27}$ of $\beta$-D-Glcp $6\left[{ }^{13} \mathrm{C}\right] \mathrm{Me}-\mathrm{OMe}(3 c)$ was recorded at $600 \mathrm{MHz}$ using the SAPPHIRE method, in which sideband artefacts were suppressed by averaging using periodic phase incrementation of residual $J$ evolution. ${ }^{28}$ A spectral width of 6 $\mathrm{kHz}$ was sampled with $16 \mathrm{k}$ data points in the direct dimension in conjunction with 16 chunks with a spectral window of $39.279 \mathrm{~Hz}$ in the indirect dimension using eight phase incrementations per chunk for sideband suppression. The final spectrum originating from concatenation of the 16 chunks was zero-filled to $32 \mathrm{k}$ data points prior to Fourier transformation. $\mathrm{A}{ }^{1} \mathrm{H}$-detected one-dimensional long-range (1DLR) experiment $^{29}$ with pulsed-field-gradients ${ }^{30}$ was used to determine the ${ }^{3} \mathrm{~J}_{\mathrm{C} 4, \mathrm{H} 6}$ coupling constants in compound 3 employing $32 \mathrm{k}$ data points per FID, an acquisition time of $2 \mathrm{~s}$ and a digital resolution of $0.5 \mathrm{~Hz}$ per data point. A nominal long-range coupling constant was set to a value of $6 \mathrm{~Hz}$ and a Gaus1_90.1000 soft pulse was used for ${ }^{13} \mathrm{C}$ resonance excitation, calibrated corresponding to a $90^{\circ}$ high power pulse duration of $14.8 \mu \mathrm{s}$. The duration of the soft pulse was chosen accordingly to the degree of selectivity needed. 1D ${ }^{1} \mathrm{H},{ }^{1} \mathrm{H}-\mathrm{NOESY}$ experiments ${ }^{31}$ with 10 different mixing times from 50 to $800 \mathrm{~ms}$ were used with an acquisition time of $4 \mathrm{~s}$ and a $120 \mathrm{~ms}$ Rsnob.1000 shaped pulse for selective excitation of the $\mathrm{H} 4$ resonance in $3 c$; suppression of zero-quantum interferences employed a $20 \mathrm{~ms}$ Chirp adiabatic pulse and a gradient strength at $5 \%$ of its maximum. NMR spectra were processed and analyzed using TopSpin 4.0.1 software (Bruker
BioSpin). Subsequent to zero-filling prior to Fourier transformation of the FID extraction of the ${ }^{3} J_{\mathrm{C} 4, \mathrm{H} 6 \mathrm{~S}}$ coupling constant in $\mathbf{3}$ was performed by the $J$ doubling procedure in the frequency domain ${ }^{32}$ using an in-house script implemented in MATLAB R2017a (MathWorks), first with a delta function for in-phase multiplets of $\left[\begin{array}{llllllll}-1 & 1 & -1 & 1 & 1 & -1 & 1 & -1\end{array}\right]$ spaced by a trial coupling constant $J^{*}$ corresponding to the in-phase vicinal and subsequently geminal coupling and then for the anti-phase doublet with a delta function of $\left[\begin{array}{llllllll}1 & 1 & 1 & 1 & -1 & -1 & -1 & -1\end{array}\right]$, in $J$ increments of $0.1 \mathrm{~Hz}$; the experimental error for ${ }^{n} J_{\mathrm{CH}}$ is estimated to be $\leq 0.2 \mathrm{~Hz}$.

Karplus Relations. The Karplus relations, with resulting scalar coupling constants in $\mathrm{Hz}$, used in this article are given below together with their references. The torsion angles are defined from the sequences (Figure $1 \mathrm{~b}$ ) O5-C5-C6-O6 $(\omega), \mathrm{C} 4-\mathrm{C} 5-\mathrm{C} 6-\mathrm{O} 6\left(\omega_{\mathrm{C}}\right), \mathrm{C} 4-\mathrm{C} 5-\mathrm{C} 6-\mathrm{H} 6 \mathrm{R}$ alternatively $\mathrm{C} 4-\mathrm{C} 5-\mathrm{C} 6-\mathrm{H} 6 \mathrm{~S}\left(\omega_{\mathrm{CH}}\right), \mathrm{C} 5-\mathrm{C} 6-\mathrm{O} 6-\mathrm{H}_{\mathrm{O} 6}$ alternatively $\mathrm{C} 5-\mathrm{C} 6-\mathrm{O} 6-\mathrm{C}_{\mathrm{Me}}(\theta), \mathrm{H} 6 \mathrm{R}-\mathrm{C} 6-\mathrm{O} 6-\mathrm{C}_{\mathrm{M}}$ alternatively H6S-C6-O6- $\mathrm{C}_{\mathrm{Me}}\left(\theta_{\mathrm{H}}\right)$.

Stenutz et al. gave the following equations: ${ }^{33}$

$$
\begin{aligned}
{ }^{3} J_{\mathrm{H} 5, \mathrm{H} 6 \mathrm{R}}= & 5.08+0.47 \cos (\omega)+0.90 \sin (\omega)-0.12 \\
& \cos (2 \omega)+4.86 \sin (2 \omega) \\
{ }^{3} J_{\mathrm{H} 5, \mathrm{H} 6 \mathrm{~S}}= & 4.92-1.29 \cos (\omega)+0.05 \sin (\omega)+4.58 \\
& \cos (2 \omega)+0.07 \sin (2 \omega)
\end{aligned}
$$

Thibaudeau et al. gave the following equation: ${ }^{34}$

$$
\begin{aligned}
{ }^{2} J_{\mathrm{H} 6 R, \mathrm{H} 6 \mathrm{~S}}= & -11.23+0.13 \cos (\omega)+0.74 \cos (2 \omega) \\
& -0.82 \cos (\theta)+2.02 \cos (2 \theta)
\end{aligned}
$$

Meredith et al. gave the following equations: ${ }^{35}$

$$
\begin{aligned}
{ }^{3} J_{\mathrm{H} 5, \mathrm{H} 6 \mathrm{R}}= & 5.22-0.42 \cos \left(\omega_{\mathrm{C}}\right)-0.04 \sin \left(\omega_{\mathrm{C}}\right)+4.21 \\
& \cos \left(2 \omega_{\mathrm{C}}\right)-2.01 \sin \left(2 \omega_{\mathrm{C}}\right) \\
{ }^{3} J_{\mathrm{H} 5, \mathrm{H} 6 \mathrm{~S}}= & 5.19+0.11 \cos \left(\omega_{\mathrm{C}}\right)-0.02 \sin \left(\omega_{\mathrm{C}}\right)-2.35 \\
& \cos \left(2 \omega_{\mathrm{C}}\right)-4.45 \sin \left(2 \omega_{\mathrm{C}}\right) \\
{ }^{2} J_{\mathrm{H} 6 R, \mathrm{H} 6 \mathrm{~S}} & -11.37-0.34 \cos \left(\omega_{\mathrm{C}}\right)+0.01 \sin \left(\omega_{\mathrm{C}}\right) \\
& -0.41 \cos \left(2 \omega_{\mathrm{C}}\right)-0.99 \sin \left(2 \omega_{\mathrm{C}}\right)
\end{aligned}
$$

Tvaroška, Hrikovini, and Petráková gave the following equation: ${ }^{36}$

$$
{ }^{3} J_{\mathrm{CH}}=0.5-0.6 \cos \left(\theta_{\mathrm{H}}\right)+5.7 \cos ^{2}\left(\theta_{\mathrm{H}}\right)
$$

Thibaudeau et al. gave the following equations: ${ }^{34}$

$$
\begin{aligned}
{ }^{3} J_{\mathrm{C} 4, \mathrm{H} 6 \mathrm{R}}= & 3.58+0.11 \cos (\omega)+3.50 \cos (2 \omega)+0.35 \\
& \sin (\omega)-0.57 \sin (2 \omega) \\
{ }^{3} J_{\mathrm{C} 4, \mathrm{H} 6 \mathrm{~S}}= & 3.60+0.50 \cos (\omega)+0.06 \cos (2 \omega)-0.13 \\
& \sin (\omega)-3.46 \sin (2 \omega)
\end{aligned}
$$

Tvaroška and Gajdoš gave the following equation: ${ }^{37}$ 


$$
\begin{aligned}
{ }^{3} J_{\mathrm{CH}}= & 5.8 \cos ^{2}\left(\omega_{\mathrm{CH}}\right)-1.6 \cos \left(\omega_{\mathrm{CH}}\right)+0.28 \sin \left(2 \omega_{\mathrm{CH}}\right) \\
& -0.02 \sin \left(\omega_{\mathrm{CH}}\right)+0.52
\end{aligned}
$$

Watson et al. gave the following equations: ${ }^{38}$

$$
\begin{aligned}
{ }^{3} J_{\mathrm{C} 4, \mathrm{H} 6 \mathrm{R}}= & 5.85 \cos ^{2}\left(\omega_{\mathrm{CH}}-0.08\right)-0.70 \\
& \cos \left(\omega_{\mathrm{CH}}+0.26\right)+0.16 \\
{ }^{3} J_{\mathrm{C} 4, \mathrm{H} 6 \mathrm{~S}}= & 5.24 \cos ^{2}\left(\omega_{\mathrm{CH}}+0.45\right)-0.12 \cos \left(\omega_{\mathrm{CH}}-1.6\right) \\
& +0.04
\end{aligned}
$$

where the phase-shifts in the latter two equations are given in radians (eq 12 has been corrected to a plus sign in the first term; personal communication with Dr A. H. Franz). Plots of all equations are shown in Supporting Information.

Molecular Dynamics Simulations. The computational model for methylated carbohydrates was built on the GROMOS carbohydrate force field, ${ }^{20}$ together with the $\mathrm{SPC} / \mathrm{E}^{39}$ potential for water. This force field was previously shown to perform better than both CHARMM $35^{18}$ and GLYCAM $06^{19}$ with respect to the hydroxymethyl conformation of cellooligomers in water; specifically it reproduces the experimentally determined weak dependence on temperature. $^{40}$ Simulations of methanol and dimethyl ether (DME) used parameters from the ATB repository ${ }^{41}$ (IDs 15607 and 21337, respectively), which are based on the GROMOS 54A7 force field. ${ }^{42}$ All molecular dynamics simulations were run using GROMACS ${ }^{43}$ version 2016 (or later) using a basic time step of 2 fs. Nonbonded interactions were cut off at $1.2 \mathrm{~nm}$, and the long-range electrostatics was included using PME. ${ }^{44,45}$ To improve sampling, all simulations were run using a replicaexchange protocol, ${ }^{46}$ with 12 replicas at different temperatures ranging from 298 to $364 \mathrm{~K}$ in $6 \mathrm{~K}$ increments, for which exchanges between neighboring replicas were attempted every 100 steps. Unless stated otherwise, properties calculated from the $298 \mathrm{~K}$ trajectory are reported. The temperatures were controlled by stochastic velocity rescaling ${ }^{47}$ and the pressure was maintained at 1 atm using the Parrinello-Rahman barostat, ${ }^{48}$ except for vacuum simulations which were run at constant volume where the temperature was controlled by the stochastic integration algorithm. ${ }^{49}$

Calculation of Free Energies. The free energies between two states (A and B) can be calculated using computational alchemy ${ }^{50}$ where the Hamiltonian is parameterized by a single parameter $\lambda$ such that $\lambda=0$ corresponds to state $\mathrm{A}$, and $\lambda=1$ corresponds to state $B$. The system can then be sampled at several intermediate values of $\lambda$ using separate simulations, and finally connected using, for example, Bennet's acceptance ratio $^{51}$ to give the free energy profile between the states. Here, to calculate free energies of solvation $\left(\Delta G_{s}\right)$, the states were chosen such that $\lambda=0$ corresponded to a state where all solute-solvent interactions were intact, and $\lambda=1$ to a state where they were completely decoupled. The free energy difference in this case (going from $\lambda=0$ to $\lambda=1$ ) is the free energy of removing the solute from the solvent, into its vapor phase $\left(-\Delta G_{s}\right)$. These simulations used $20 \lambda$-points, each simulated for 5 ns with replica exchange. Alternatively, the difference in solvation free energy, $\Delta \Delta G_{s}$, between two different species (e.g., a nonmethylated and methylated carbohydrate) can be calculated using the same method, but where state $\mathrm{A}$ is the nonmethylated solute, and $\mathrm{B}$ is the methylated one (Figure 1c). Here, the transition between the end states involves the "mutation" of the hydroxyl proton into a $\mathrm{CH}_{3}$ group (which is a single interaction site in the GROMOS united atoms representation), with consequences on both nonbonded and bonded interaction terms. The difference between the free energies obtained in this way from simulations in both solvent and vacuum corresponds to $\Delta \Delta G_{s}$ between the original and the methylated solute, $\Delta \Delta G_{s}$ $=\Delta G_{s}^{\mathrm{OMe}}-\Delta G_{\mathrm{s}}^{\mathrm{OH}}=\Delta G_{\mathrm{mut}}^{\mathrm{wat}}-\Delta G_{\mathrm{mut}}^{\mathrm{vac}}$ due to that the thermodynamic cycle must add up to zero (Figure 1c), and is thus a measure of the effect of methylation itself. For these simulations, $25 \lambda$-points were used, each simulated for $2 \mathrm{~ns}$, employing temperature replica exchange as described above. This protocol was recently used for simulations of acetylated cellooligomers and cellulose nanocrystals. ${ }^{52}$

\section{RESULTS AND DISCUSSION}

The monosaccharide glucose, methyl derivatives thereof and a pseudo-monosaccharide were chosen as models for NMR experiments and computational studies, viz., $\beta$-D-Glcp (1), $\beta$-DGlcp-OMe (2), its 6-O-methylated derivative $\beta$-D-Glcp6Me$\mathrm{OMe}$ (3), and the pyran derivative (4) (Figure 2). The 6-Omethylated glucosides were synthesized via a three-step procedure from the fully protected methyl 2,3-di-O-benzyl4,6-O-benzylidine- $\beta$-D-glucopyranoside by regioselective ringopening reduction of the 4,6-O-benzylidene group, ${ }^{53}$ alkylation with methyl iodide or $\left[{ }^{13} \mathrm{C}\right]$ methyl iodide, and removal of the benzyl ether groups ${ }^{54}$ to give $\beta$-D-Glcp6Me-OMe (3), ${ }^{55}$ and $\beta$ D-Glcp6 $\left[{ }^{13} \mathrm{C}\right] \mathrm{Me}-\mathrm{OMe}(3 c)$, respectively (see Supporting Information). These 6-O-methylated monosaccharide derivatives of glucose facilitate a detailed analysis of conformational dynamics, related to entities of MC.

NMR Experiments for Conformational Analysis of Monosaccharides. The ${ }^{1} \mathrm{H}$ NMR resonance assignments for $\mathrm{H} 6 \mathrm{R}$ and $\mathrm{H} 6 \mathrm{~S}$ in $\beta$-D-Glcp-OMe are known based on selective deuteration methodology. ${ }^{56}{ }^{3} \mathrm{~J}_{\mathrm{H}, \mathrm{H} 6}$, which may be used to determine the population distribution of the $\omega$ torsion angle, as well as ${ }^{2} J_{\mathrm{H} 6 R, \mathrm{H} 6 \mathrm{~S}}$ were determined by total lineshape analysis $^{26}$ (Table 1), in full agreement with previously reported values. ${ }^{56-58}$ For $\beta$-D-Glcp6Me-OMe, the ${ }^{1} \mathrm{H}$ NMR spectrum showed resolved resonances for the protons of the hydroxymethyl group (Figure 3a), and in $\beta$-D-Glcp $6\left[{ }^{13} \mathrm{C}\right] \mathrm{Me}$ $\mathrm{OMe}$ additional couplings were present; these scalar interactions originate from the ${ }^{13} \mathrm{C}$-labeled methyl group (Figure $3 b$ ), evident also in the pure shift ${ }^{1} \mathrm{H}$ NMR spectrum (Figure 3c). To assign the resonances from H6R and H6S in $\beta$ D-Glcp6Me-OMe, a series of $1 \mathrm{D}{ }^{1} \mathrm{H},{ }^{1} \mathrm{H}-\mathrm{NOESY}$ experiments were used with selective excitation of the $\mathrm{H} 4$ resonance, resulting for the resonances at 3.64 and $3.79 \mathrm{ppm}$ in a relative ratio of 2.3:1 at the longest mixing time (Figure 4a). By considering that 1,3-diaxial interactions, corresponding to a syn-pentane relationship, ${ }^{59,60}$ between hydroxyl groups in sugars are energetically disfavored, ${ }^{61}$ the NOE results facilitate assignment of the resonance at $3.64 \mathrm{ppm}$ to $\mathrm{H} 6 \mathrm{R}$ and the one at $3.79 \mathrm{ppm}$ to $\mathrm{H} 6 \mathrm{~S}$. The ${ }^{1} \mathrm{H},{ }^{13} \mathrm{C}$-heteronuclear ${ }^{3} \mathrm{~J}_{\mathrm{H} 6, \mathrm{Me}}$ in $\beta$-DGlcp $6\left[{ }^{13} \mathrm{C}\right] \mathrm{Me}$-OMe were determined by the total lineshape fitting procedure (Table 1 ). The ${ }^{3} J_{\mathrm{C} 4, \mathrm{H} 6}$ coupling constants related to the $\omega_{\mathrm{C}}$ torsion angle were obtained by a ${ }^{1} \mathrm{H}$-detected one-dimensional long-range (1DLR) experiment ${ }^{29,30}$ (Figure $4 \mathrm{~b}$ ) followed by extraction of the ${ }^{3} J_{\mathrm{C} 4, \mathrm{H} 6 \mathrm{~S}}$ coupling constant by the $J$ doubling procedure in the frequency domain ${ }^{32}$ resulting in a relatively large value of $2.5 \mathrm{~Hz}$ (Table 1 ). However, the ${ }^{3} J_{\mathrm{C} 4 \mathrm{H}, \mathrm{R}}$ coupling constant was smaller and from the anti-phase 
Table 1. Experimental and Computed NMR Spin-Spin Coupling Constants (Hz) in $\beta$-D-Glcp-OMe (2) and $\beta$-DGlcp6Me-OMe (3)

\begin{tabular}{lllll} 
coupled nuclei & \multicolumn{2}{c}{ NMR } & \multicolumn{3}{c}{ molecular dynamics } \\
& \multicolumn{5}{c}{ Compound 2 } \\
H5,H6R & 6.15 & $6.62^{a}$ & $6.28^{c}$ & \\
H5,H6S & 2.25 & $2.43^{a}$ & $2.94^{c}$ & \\
H6R,H6S & -12.33 & $-11.23^{b}$ & $-11.65^{c}$ & \\
C4,H6R & $1.0^{h}$ & $2.12^{b}$ & $1.50^{d}$ & $3.85^{e}$ \\
C4,H6S & $2.4^{h}$ & $3.03^{b}$ & $3.45^{d}$ & \\
& & Compound 3 & & \\
H5,H6R & 6.35 & $7.15^{a}$ & $6.71^{c}$ & \\
H5,H6S & 2.09 & $2.26^{a}$ & $2.71^{c}$ & \\
H6R,H6S & -11.26 & $-9.92^{b}$ & $-11.66^{c}$ & \\
Me,H6R & $3.16^{i}$ & $2.64^{f}$ & & \\
Me,H6S & $2.69^{i}$ & $2.20^{f}$ & & \\
Me,C5 & $3.4^{i}$ & $4.99^{g}$ & & $3.91^{e}$ \\
C4,H6R & $<1.2^{j}(1.0)^{h}$ & $1.98^{b}$ & $1.39^{d}$ & \\
C4,H6S & $2.5^{j}(2.45)^{h}$ & $2.72^{b}$ & $3.15^{d}$ &
\end{tabular}

${ }^{a}$ Karplus-type relationships used in the simulations: ${ }^{3} J_{\mathrm{HH}}$ from Stenutz et al. ${ }^{33}$ Karplus-type relationships used in the simulations: ${ }^{2} J_{\mathrm{HH}}$ and ${ }^{3} J_{\mathrm{CH}}$ from Thibaudeau et al. ${ }^{34}$ Karplus-type relationships used in the simulations: ${ }^{n} J_{\mathrm{HH}}$ from Meredith et al. ${ }^{35}{ }^{d}$ Karplus-type relationships used in the simulations: ${ }^{3} J_{\mathrm{CH}}$ from Tvaroška et al. (1995). ${ }^{37}{ }^{e}$ Karplustype relationships used in the simulations: ${ }^{3} \mathrm{~J}_{\mathrm{CH}}$ from Watson et al. ${ }^{38}$ ${ }^{f}$ Karplus-type relationships used in the simulations: ${ }^{3} J_{\mathrm{CH}}$ from Tvaroška et al. (1989). ${ }^{36}{ }^{g}$ Karplus-type relationships used in the simulations: JCC/SU21. ${ }^{h}$ Experimental ${ }^{3} J_{\mathrm{CH}}$ data: Tvaroška et al. (2002). ${ }^{58}{ }^{i}$ Experimental ${ }^{3} J_{\mathrm{CH}}$ data: determined from $\beta$-D-Glcp $6\left[{ }^{13} \mathrm{C}\right]$ Me-OMe (3c). ${ }^{j}$ Experimental ${ }^{3} J_{\mathrm{CH}}$ data: from $\beta$-D-Glcp6Me-OMe (3).

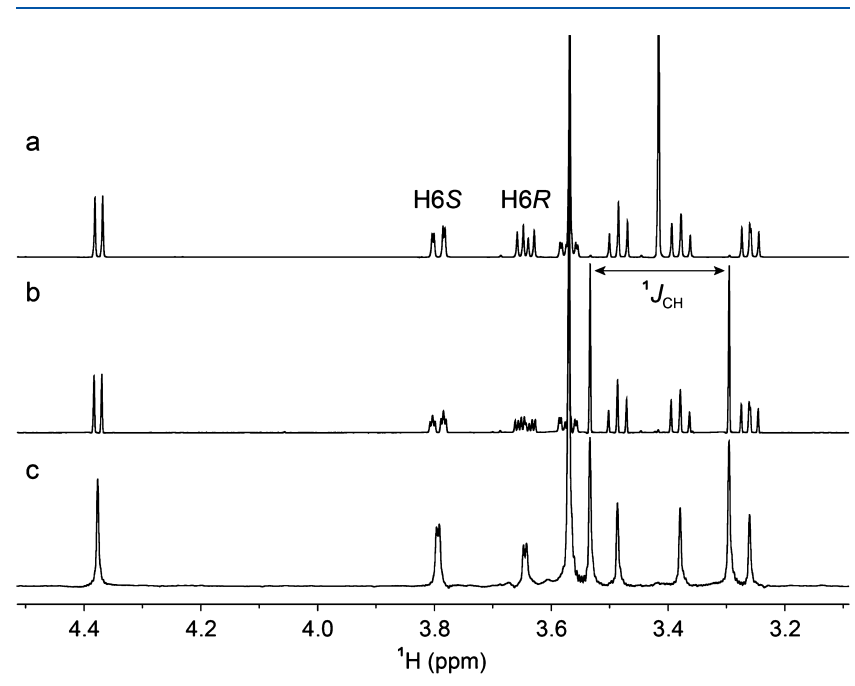

Figure 3. ${ }^{1} \mathrm{H}$ NMR spectra at $600 \mathrm{MHz}$ of compounds in $\mathrm{D}_{2} \mathrm{O}$ at 298 $\mathrm{K}:$ (a) $\beta$-D-Glcp6Me-OMe (3), (b) $\beta$-D-Glcp6 $\left[{ }^{13} \mathrm{C}\right] \mathrm{Me}-\mathrm{OMe}(3 c)$, and (c) pure shift ${ }^{1} \mathrm{H}$ NMR spectrum of compound $3 c$.

peak separation, its value was estimated ${ }^{62}$ to be $<1.2 \mathrm{~Hz}$ (Table $1)$; these coupling constants are in excellent agreement with previously determined ${ }^{3} J_{\mathrm{C} 4, \mathrm{H} 6}$ values ${ }^{58}$ obtained by a different NMR experiment, and similar in magnitude to other glucopyranosides. ${ }^{63,64}$ The ${ }^{13} \mathrm{C},{ }^{13} \mathrm{C}$-homonuclear ${ }^{3} J_{\mathrm{C} 5, \mathrm{Me}}$ coupling (Table 1) in $\beta$-D-Glcp $6\left[{ }^{13} \mathrm{C}\right] \mathrm{Me}-\mathrm{OMe}$ was readily determined from the doublet of the $\mathrm{C} 5$ resonance in the $1 \mathrm{D}$ ${ }^{13} \mathrm{C}$ NMR spectrum.

Conformational Analysis of Exo-Cyclic Torsions Using Limiting Values for ${ }^{3} J_{\mathrm{H} 5, \mathrm{H} 6}$ and ${ }^{3} J_{\mathrm{H} 6, \mathrm{Me}}$. The rotamer

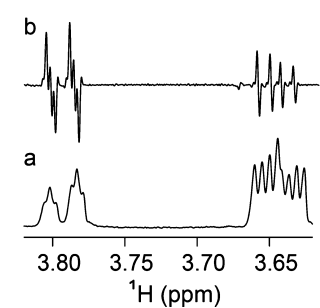

Figure 4. Selected ${ }^{1} \mathrm{H}$ NMR spectral region of $\mathrm{H} 6$ protons of (a) a $1 \mathrm{D}$ ${ }^{1} \mathrm{H},{ }^{1} \mathrm{H}$-NOESY NMR spectrum at $700 \mathrm{MHz}$, with a mixing time of $800 \mathrm{~ms}$, of $\beta$-D-Glcp $6\left[{ }^{13} \mathrm{C}\right] \mathrm{Me}-\mathrm{OMe}(3 c)$ in $\mathrm{D}_{2} \mathrm{O}$ at $298 \mathrm{~K}$ in which the $\mathrm{H} 4$ resonance was selectively excited and (b) a ${ }^{1} \mathrm{H},{ }^{13} \mathrm{C}$ heteronuclear one-dimensional long-range (1DLR) spectrum of the corresponding spectral region and experimental conditions for $\beta$-DGlcp6Me-OMe (3) in which the $\mathrm{C} 4$ resonance was selectively excited.

distribution at the $\omega$ and $\theta$ torsion angles (Figure 2) can be analyzed using a three-state model in which the limiting ${ }^{3} J_{\mathrm{H} 5, \mathrm{H} 6}$ and ${ }^{3} \mathrm{~J}_{\mathrm{H} 6, \mathrm{Me}}$ values, respectively, of the conformational states are used together with the fact that the sum of populations for a given torsion is equal to unity. For the $\omega$ torsion angle, the limiting values are according to Stenutz et al. ${ }^{33}$ calculated for $g t$ $=+65^{\circ}, g g=-65^{\circ}$ and $t g=180^{\circ}$ whereas Amarasekhara et al. ${ }^{.5}$ utilized ideal staggered conformations. In deciding on a suitable Karplus-type relationship for the $\theta$ torsion angle for calculation of the limiting values with $g^{+}=+60^{\circ}, g^{-}=-60^{\circ}$ and $t=180^{\circ}$, we relied on the recent results from DFT calculations of ${ }^{3} \mathrm{~J}_{\mathrm{CH}}$ coupling constants by $\mathrm{Li}$ et al., ${ }^{66}$ and choose the parametrization by Tvaroška et al. ${ }^{36} \mathrm{~A}$ schematic representation of the three conformational states of the $\omega$ torsion angle in conjunction with different states of the $\theta$ torsion angle is depicted in Figure 5. Whereas the parametrization by Stenutz et al. ${ }^{33}$ favors the $g t$ conformational state over $\mathrm{gg}$, that of Amarasekhara et al. ${ }^{65}$ results in a

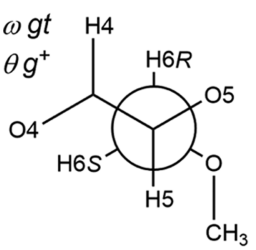

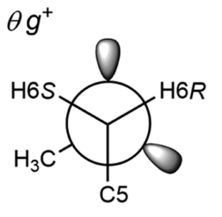

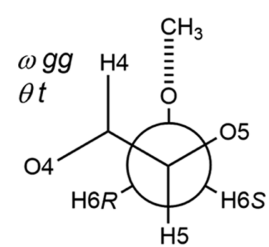

$\theta t$

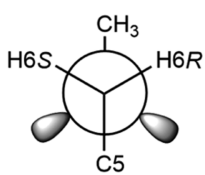

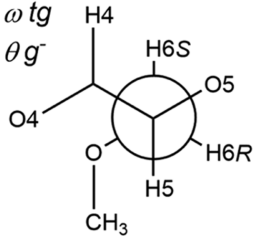

$\theta g^{-}$

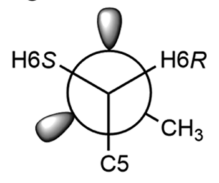

Figure 5. Newman projections along the $\mathrm{C} 5-\mathrm{C} 6$ bond in $\beta$-DGlcp6Me-OMe (3). The staggered conformers are for the $\omega$ torsion angle (left side) referred to as $g t$ (top), $g g$ (middle), and $t g$ (bottom) and the $\theta$ torsion angle is exemplified by $g^{+}$(top), $t$ (middle), and $g^{-}$ (bottom). The Newman projections along the $\mathrm{C} 6-\mathrm{O} 6$ bond for the $\theta$ torsion angle are given in an analogous way (right side). 
population where $g t \approx g g$ for $\beta$-D-Glcp-OMe (Table 2) using the herein collected NMR data, like previously observed. This is also the case for $\beta$-D-Glcp6Me-OMe, consistent with the results of Dahruman et al. ${ }^{60}$ who showed that the effect of the substituent group at $\mathrm{O} 6$ is small on the conformational distribution at the $\omega$ torsion angle. The error in the derived rotamer populations of the $\omega$ torsion angle is estimated to be $<5 \%$.

Based on the limiting heteronuclear ${ }^{3} J_{\mathrm{H} 6, \mathrm{Me}}$ values for $\beta$-DGlcp6Me-OMe, the rotamer distribution of the $\theta$ torsion angle (Figure 5) was determined as $t>g^{+}>g^{-}$(Table 2). The error in the derived rotamer populations of the $\theta$ torsion angle is estimated to be $<10 \%$. In the case of a bulky O-tritylated group substituting position 6 of a glucosyl derivative, the trans conformation of the $\theta$ torsion angle was highly populated $(88 \%) .^{33}$ From DFT calculations on a pseudo-saccharide, it has been shown that ${ }^{2} J_{\mathrm{H} 6 \mathrm{R}, \mathrm{H} 6 \mathrm{~S}}$ is considerably less negative when the torsion angle $\theta$ has an antiperiplanar arrangement $(t)$, in contrast to when it is in either of the synclinal arrangements $\left(g^{+}\right.$or $\left.g^{-}\right)$. Whereas, ${ }^{2} J_{\mathrm{H} 6 R, \mathrm{H} 6 S}$ is highly dependent on the torsion angle $\theta$, it varies to a smaller extent as a function of the $\omega$ torsion angle. ${ }^{34}$ Thus, that ${ }^{2} J_{\mathrm{H} 6 \mathrm{R}, \mathrm{H} 6 \mathrm{~S}}$ is less negative in the 6-O-methylated derivative 3 compared to the unsubstituted analogue $\mathbf{2}$ (Table 1 ) is consistent with a significantly populated $t$ state in $\beta$-D-Glcp6Me-OMe.

Karplus-Type Equation for 6-O-Methylated Hexopyranoses. Calculations of NMR spin-spin coupling constants by theoretical methods are highly valuable in conformational analysis of saccharides ${ }^{17,67}$ and can form the basis for developing and/or improving Karplus-type relationships that subsequently can be used on their own in studies of oligo- and polysaccharide conformation and dynamics. To reduce the complexity and to increase the computational efficiency, pseudo-saccharides devoid of hydroxyl groups can be utilized in quantum mechanical calculations of conformational preferences ${ }^{68}$ and such a model (compound 4) was available from the literature for which ${ }^{3} J_{\mathrm{COCC}}$ coupling constants had been calculated as a function of torsion angle

Table 2. Rotamer Populations for $\omega$ and $\boldsymbol{\theta}$ Torsion Angles in $\beta$-D-Glcp (1), $\beta$-D-Glcp-OMe (2), and $\beta$-D-Glcp6Me-OMe (3) from MD Simulations and NMR Experiments

\begin{tabular}{|c|c|c|c|c|}
\hline \multirow[b]{2}{*}{ compound } & \multirow[b]{2}{*}{ method } & \multicolumn{3}{|c|}{$\omega$ rotamer distribution $(\%)$} \\
\hline & & $g t$ & $g g$ & $\operatorname{tg}$ \\
\hline 1 & $\mathrm{MD}$ & 59 & 38 & 3 \\
\hline \multirow[t]{3}{*}{2} & $\mathrm{NMR}^{a}$ & 55 & 36 & 9 \\
\hline & $\mathrm{NMR}^{b}$ & 51 & 49 & 0 \\
\hline & $\mathrm{MD}$ & 65 & 32 & 3 \\
\hline \multirow[t]{3}{*}{3} & $\mathrm{NMR}^{a}$ & 58 & 35 & 7 \\
\hline & $\mathrm{NMR}^{b}$ & 53 & 47 & 0 \\
\hline & $\mathrm{MD}$ & 72 & 27 & 1 \\
\hline & & \multicolumn{3}{|c|}{$\theta$ rotamer distribution (\%) } \\
\hline compound & method & $g^{+}$ & $t$ & $g^{-}$ \\
\hline 1 & $\mathrm{MD}$ & 30 & 43 & 27 \\
\hline 2 & $\mathrm{MD}$ & 27 & 46 & 27 \\
\hline \multirow[t]{2}{*}{3} & $\mathrm{NMR}^{c}$ & 30 & 50 & 20 \\
\hline & $\mathrm{MD}$ & 18 & 78 & 4 \\
\hline
\end{tabular}

${ }^{a}$ Limiting coupling constants from ${ }^{a}$ Stenutz et al. ${ }^{33} b$ Limiting coupling constants from Amarasekhara et al. ${ }^{65}{ }^{c}$ Limiting coupling constants from Tvaroška et al. ${ }^{36}$ rotation. ${ }^{69}$ Based on these computed data, we herein propose a Karplus-type relationship denoted JCC/SU21 given by

$$
\begin{aligned}
{ }^{3} J_{\text {COCC }}= & 3.20-0.20 \cos (\theta)-0.18 \sin (\theta)+3.35 \\
& \cos (2 \theta)-0.42 \sin (2 \theta)
\end{aligned}
$$

related to the $\mathrm{C} 5-\mathrm{C} 6-\mathrm{O} 6-\mathrm{C}_{\mathrm{Me}}$ torsion angle $\theta$ (Figure 6). In comparison to the Karplus-type relationship given for methoxyethane that has its maximum at $0^{\circ}$ as presented by Hadad et al., ${ }^{17}$ one can note that JCC/SU21 instead has its maximum at $\sim 180^{\circ}$, with a minute phase shift of the curve of only $-4^{\circ}$, as the electronegative ring oxygen is a terminal substituent to the coupling path. ${ }^{69}$ With the homonuclear ${ }^{3} \mathrm{~J}_{\mathrm{C} 5, \mathrm{Me}}$ coupling constant determined from $\beta$-D-Glcp $6\left[{ }^{13} \mathrm{C}\right] \mathrm{Me}-$ $\mathrm{OMe}$ and a pertinent Karplus-type relationship implemented, conformational analysis can be extended further in conjunction with MD simulations.

Molecular Dynamics Simulations of Monosaccharides with Comparison to Experiments. MD simulations were performed of compounds $\mathbf{1}$ to 3 in water, and the rotamer distributions of $\omega$ and $\theta$ were sampled (Figure 7). The simulations show that both $\omega$ and $\theta$ are affected by methylation. For $\omega$, the population in gt increases slightly from glucopyranose to the methyl glucopyranoside, and then further upon 6-O-methylation, in both cases at the expense of gg. The population in $t g$ remains small and relatively unaffected. Although the differences are small, this trend is supported also by calculated populations from NMR (Table 2) with respect to the difference between compounds 2 and 3 .

The simulated distributions for $\theta$ are almost identical for compounds 1 and 2, displaying a close to even distribution between the three conformational states with a small predominance for trans conformation. This implies that an O-methyl group at $\mathrm{C} 1$ does not affect the rotation of the hydroxyl group at C6. With O-methylation in position six, the population in gauche almost vanishes completely, and the trans conformer becomes the dominating one. This trend is again supported by the experiments (Table 2) although the effect is not as dramatic.

The rotamer states of $\omega$ and $\theta$ in glucose-based monosaccharides were previously shown to be correlated. ${ }^{34}$ For that reason, distributions of $\theta$ in compounds $\mathbf{2}$ and $\mathbf{3}$ were calculated separately for the cases of having $\omega$ in either $t g$, $g t$, or $g g$ (Figure 7). Interestingly, $\theta$ depends weakly on $\omega$ in the nonO6-methylated compound, where the $g t$ and $g g$ conformations favor having $\theta$ in $g-$ and $g+$, respectively. With a methyl group on $\mathrm{O6}$, the correlation becomes stronger. Specifically, although

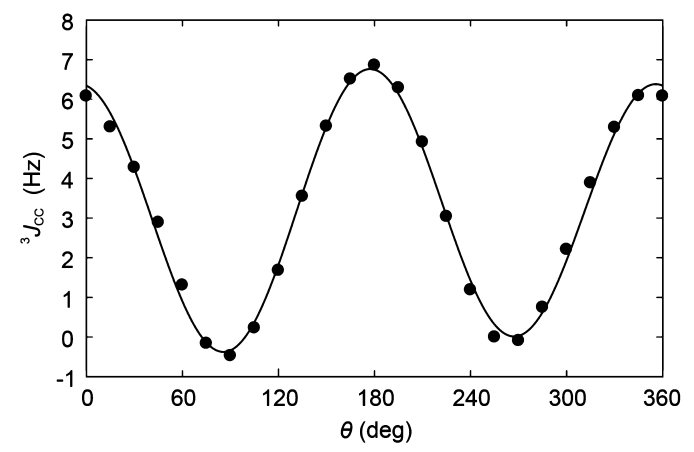

Figure 6. Karplus-type relationship (solid line) for the $\theta$ torsion angle in compound 3 derived from calculated ${ }^{3} J_{\mathrm{COCC}}$ values (filled circles). 

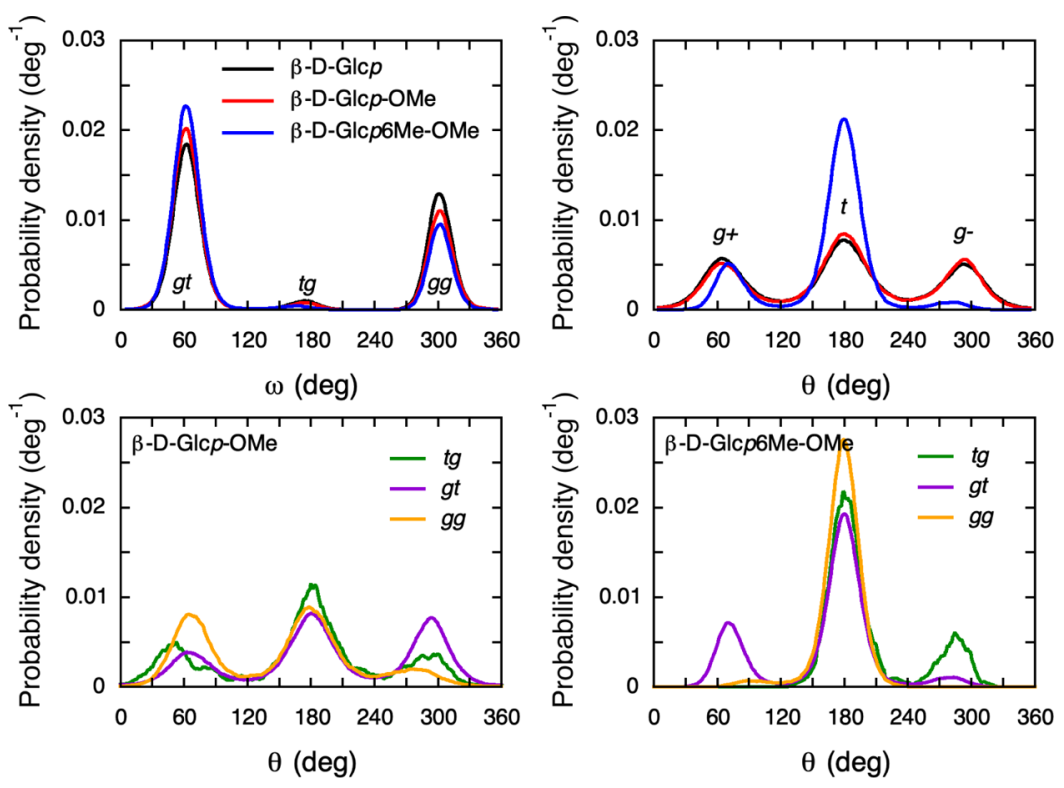

Figure 7. Top row: Distributions of the torsion angles $\omega$ (left) and $\theta$ (right) for the three monosaccharides from simulations at $298 \mathrm{~K}$. Bottom row: Distributions of $\theta$ extracted from compounds 2 (left) and 3 (right) with $\omega$ in either of the three states: $t g, g t$, or $g g$.

trans dominates for $\theta$ in all cases, with $\omega$ in $g g$, only the trans conformation is permitted.

The population distributions for $\omega$ at different temperatures were also calculated from the simulations (Figure 8). The populations show only weak dependence on temperature, which is in line with previous simulation results on both methylated and nonmethylated saccharides. ${ }^{21,40,70}$ Interestingly, the small difference between compounds $\mathbf{1}$ and $\mathbf{2}$ vanishes at increased temperatures, but the difference to compound 3 remains.

From the simulated distributions, NMR coupling constants for compounds $\mathbf{2}$ and $\mathbf{3}$ were calculated using the appropriate Karplus-type relationships. The overall agreement between experimentally determined $J$ coupling constants is good (Table $1)$, although an even better agreement would require additional fine-tuning of the GROMOS 56 carbohydrate force field and as such could reveal the Karplus equations to be used preferably. By an NMR experiment based on heteronuclear ${ }^{3} \mathrm{~J}_{\mathrm{H} 6 \mathrm{Me}}$ couplings, the trans conformational state for the $\theta$ torsion angle of compound 3 was determined to be the major one, which indeed was the case also in the MD

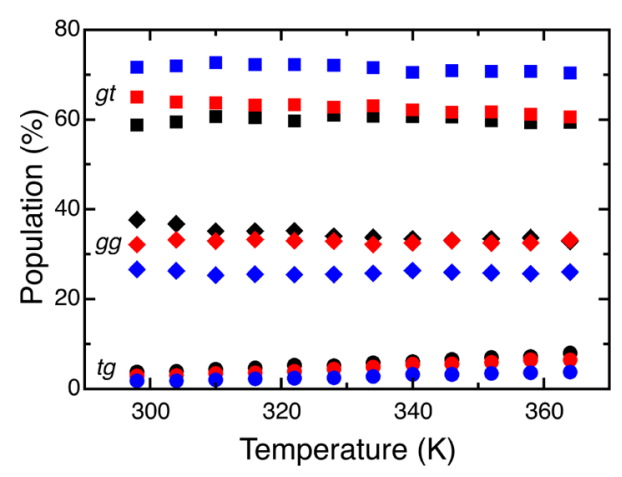

Figure 8. Populations of $\omega$ rotamers: $\operatorname{tg}$ (circles), $g g$ (diamonds), and gt (squares), as a function of temperature for the three monosaccharides: $\beta$-D-Glcp (black), $\beta$-D-Glcp-OMe (red), and $\beta$-DGlcp6Me-OMe (blue). simulations. However, simulation overestimates this conformational preference somewhat, furthermore stressed by the computed homonuclear ${ }^{3} J_{\mathrm{C} 5, \mathrm{Me}}$ coupling, which is larger than determined from experiment. This observation supports the fact that the herein proposed Karplus-type relationship for ${ }^{3} J_{\text {COCC }}$ (Figure 6 and eq 13) referred to as 3JCC/SU21 will be a useful complement in the conformational analysis of oligoand polysaccharides.

Solution Thermodynamics of Methylated Monosaccharides from Simulations. In addition to a solution structure, it is interesting to investigate whether the model can capture relevant solvation thermodynamics of the model compounds. Experimental data is scarce, but Jasra and Ahluwalia ${ }^{71}$ have reported experimental partial molar volumes $\left(V_{2}^{0}\right)$ for $\beta$-D-Glcp and $\beta$-D-Glcp-OMe at infinite dilution, which shows the effect of methylation at O1. Partial molar volumes were thus calculated from long equilibrium simulations of a single sugar molecule in water and compared to simulations of pure water. Simulated values for $V_{2}^{0}$ are high compared to experimental data (Table 3), and the volume per glucose molecule is more than $13 \%$ higher in the simulations. By comparing $V_{2}^{0}$ for both methylated and non-methylated sugars, the change in $V_{2}^{0}$ resulting from methylation, $\Delta V_{2}^{0}$, is calculated. The calculated increase, $\Delta V_{2}^{0}$, for the 1-O-methyl substitution in simulations is close to the experimental value in absolute numbers, but still $16 \%$ higher in relative terms. For the 6-Omethylation, for which there is no experimental result, the calculated $\Delta V_{2}^{0}$ is higher than for methylation at $\mathrm{O} 1$. This is

Table 3. Partial Molar Volumes at Infinite Dilution in $\mathrm{cm}^{3}$ $\mathrm{mol}^{-1}$

$\begin{array}{lcccc} & V_{2}^{0}\left(\operatorname{sim}^{a}\right) & \Delta V_{2}^{0}(\operatorname{sim}) & V_{2}^{0}\left(\operatorname{expt}^{b}\right) & \Delta V_{2}^{0}\left(\operatorname{expt}^{b}\right) \\ \beta \text {-D-Glcp } & 126.7 & & 111.7 & \\ \beta \text {-D-Glcp-OMe } & 144.3 & 17.6 & 132.1 & 20.4 \\ \beta \text {-D-Glcp6Me-OMe } & 163.7 & 19.4 & & \end{array}$

${ }^{a}$ Statistical error is on the order of $0.5 \mathrm{~cm}^{3} \mathrm{~mol}^{-1} \cdot{ }^{b}$ Experimental values from Jasra and Ahluwalia. ${ }^{71}$ 
Table 4. Calculated and Experimental Solvation Free Energies $\Delta G_{\mathrm{s}}$ in $\mathrm{kJ} \mathrm{mol}^{-1}$

$\begin{array}{cccccc} & \mathrm{MeOH} & \mathrm{DME} & \beta \text {-D-Glcp } & \beta \text {-D-Glcp-OMe } & \beta \text {-D-Glcp6Me-OMe } \\ \Delta G_{\mathrm{s}}^{\text {calc }} & -17.7 \pm 0.1 & -2.64 \pm 0.1 & -68.0 \pm 0.2 & -54.7 \pm 0.1 & -44.5 \pm 0.2 \\ \Delta G_{\mathrm{s}}^{\text {expt }} & -21.32^{a} & -7.94^{a} & -106.8 \pm 0.9^{b} & & \\ { }^{a} \text { From ref } 77 . & & \\ & & & & & \\ \end{array}$

likely a reflection of the higher degree of hydration of the hydroxyl group at $\mathrm{C} 6$ than of the one at $\mathrm{C} 1$, as a methyoxy group constitutes a larger perturbation to the solvent.

The free energy of solvation $\Delta G_{s}$ was computed by decoupling all solute-solvent interactions, as described in the Methods section, for the three monosaccharides in water (Table 4). The computed $\Delta G_{s}$ values are large and negative, indicating a strong preference for the solvated state over the vapor phase, as expected. The calculated $\Delta G_{s}$ for $\beta$-D-Glcp, $-68.0 \mathrm{~kJ} \mathrm{~mol}^{-1}$, compare reasonably well to other values found in the literature. Klimovich and Mobley calculated it to $-71 \mathrm{~kJ}$ mol $^{-1}$ using the General Amber Force Field, ${ }^{72}$ and López et al. obtained $-89 \mathrm{~kJ} \mathrm{~mol}^{-1}$ using GROMOS $45 .^{73}$ The simulations furthermore show a clear effect of methylation: $\Delta G_{s}$ increases by more than $10 \mathrm{~kJ} \mathrm{~mol}^{-1}$ as a result of having an additional methyl group in both the $\mathrm{O} 1$ and $\mathrm{O} 6$ positions. This is a direct consequence of replacing polar hydroxyl groups with non-polar methyl groups, which makes the solutes considerably less hydrophilic.

Solvation free energies of large nonvolatile solutes such as monosaccharides are not trivial to determine experimentally. For D-glucose, experimental vapor pressures are available, ${ }^{74}$ which together with its molar solubility in water can be used to calculate the solvation free energy. Based on experimental data, $\Delta G_{s}$ for D-Glcp becomes $-106.8 \mathrm{~kJ} \mathrm{~mol}^{-1}$, which is considerably larger than the values from the present simulations of monosaccharides. In fact, the solvation free energy of sugars is notoriously difficult to predict using computational methods: in the SAMPL2 blind prediction challenge $^{75}$ half of the contributions (using a wide array of different models) missed the experimental $\Delta G_{\mathrm{s}}$ for D-glucose by more than $25 \mathrm{~kJ} \mathrm{~mol}^{-1}$. The relative complexity and flexibility of the sugar molecules leading to difficulties to achieve converged sampling were mentioned as a likely cause, although here, with the use of REMD and long simulations this is less probable. A more plausible explanation in our opinion is the inherent inaccuracy of the force field parameters which can have dramatic effects on solvation-free energies. Some empirical force fields have been shown to systematically underestimate the solvation-free energy of sugars and other hydroxyl-rich compounds, presumably due to poor optimization of alcohols. ${ }^{12}$ Furthermore, it has been shown that depending on which charge equilibration scheme was used in the model development, the calculated solvation free energy of glucose could differ by as much as $60 \mathrm{~kJ} \mathrm{~mol}^{-1}$. $^{76}$

However, despite difficulties to reproduce absolute solvation free energies simulations can still be useful. The peculiar phase behavior of hydrated MC likely depends on a delicate balance between the solvation energies of its methylated and nonmethylated parts. Therefore, it is more important that the model replicates differences in solvation free energy, $\Delta \Delta G_{s}$, between the methylated and non-methylated model compounds. However, because, to the best of our knowledge, no experimental hydration-free energies for the methylated sugars are available, a slightly different approach is taken which is described in the next section.
Free Energy of Solvation of Small Model Compounds. In order to validate the free energy difference between hydroxyl and O-methyl groups, simulations were performed using small model compounds. The test solutes opted for were methanol $(\mathrm{MeOH})$ and DME, which differ in that the $\mathrm{OH}$ group in $\mathrm{MeOH}$ is substituted for an O-methyl group. Importantly, the calculated values can be compared to available experimental data for the hydration-free energies, which can be derived from tabulated Henry's law constants at infinite dilution. ${ }^{77}$

The calculated values of $\Delta G_{s}$ for both $\mathrm{MeOH}$ and DME are too small compared to experimental data, differing by 3.6 and $5.3 \mathrm{~kJ} \mathrm{~mol}^{-1}$, respectively (Table 4). This is in line with that $\Delta G_{s}$ for the sugars were also underestimated, although the fact that the error is larger for DME shows that it is not only the $\mathrm{OH}$ groups that are to blame. On the other hand, the difference between the two, $\Delta \Delta G_{s}$, which is of greater importance for the present work is slightly overestimated by the simulations (Table 5) and differs by only $1.7 \mathrm{~kJ} \mathrm{~mol}^{-1}$ from the experimental value. This is reassuring because it suggests that the present parameters correctly reproduce both the sign and, within reasonable accuracy, the magnitude of the change in solvation free energy when hydroxyl groups are transformed into O-methyl groups, also in more complex compounds.

Free Energy of Solvation from Computational Alchemy. It is not obvious that properties for monosaccharides automatically can be extrapolated to oligo- or polysaccharides, such as cellulose, and for that reason, calculations on larger solutes were undertaken. However, the method used above is not well suited for computing solvation-free energies of complex molecules such as oligosaccharides, due to the long simulations needed to ensure convergence. Here, we take a slightly different approach and consider the change in free energy of transforming the non-methylated oligosaccharide into its methylated counterpart using computational alchemy (see Methods). Because this transformation constitutes a much smaller change than decoupling the whole oligosaccharide from the solvent, much more rapid convergence can be expected. It can be noted that this is similar to the approach taken by $\mathrm{Yu}$ et al. ${ }^{24}$ where the mutations were treated as singlestep perturbations, that is, without intermediate states in $\lambda$.

To validate our approach, the alchemical transformations were performed on both monosaccharides and on $\mathrm{MeOH}$ for which the $\Delta G_{\mathrm{s}}$ was already calculated. In this way, all paths in the thermodynamic cycle can be independently assessed, and the internal consistency can be checked. For the case of the transformation of $\mathrm{MeOH}$ into DME, $\Delta \Delta G_{\mathrm{s}}$ was $1.2 \mathrm{~kJ} \mathrm{~mol}^{-1}$

Table 5. Differences in Solvation Free Energy $\Delta \Delta G_{\mathrm{s}}$ in $\mathrm{kJ}$ $\mathrm{mol}^{-1}$

$\mathrm{MeOH} / \mathrm{DME} \quad \beta$-D-Glcp-OMe/ $\beta$-D-Glcp6Me-OMe

$\begin{array}{lll}\text { experimental } & 13.38 & \\ \text { solvation } & 15.1 \pm 0.2 & 10.2 \pm 0.3 \\ \text { mutation: } \Delta G_{\text {mut }}^{\text {wat }}- & 13.9 \pm 0.1 & 10.6 \pm 0.1\end{array}$

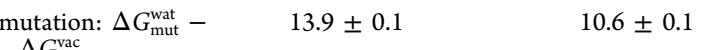

$\Delta G_{\mathrm{mut}}^{\mathrm{vac}}$ 
smaller when calculated from the mutations compared to the full decoupling simulations. This value was thus closer to the experimental result, differing by as little as $0.5 \mathrm{~kJ} \mathrm{~mol}^{-1}$. For the case of monosaccharides, the difference between the alchemical transformation and the decoupling was even smaller, only $0.4 \mathrm{~kJ} \mathrm{~mol}^{-1}$ (Table 5), indicating good internal consistency.

Thus, although absolute solvation free energies are not particularly well reproduced by simulations, we conclude that the present parameters reproduce the free energy change of methylation with sufficient accuracy, and further that the considerably less computationally expensive method of alchemical mutation of hydroxyl groups reflects that change in a satisfactory manner.

Simulation of Methylated Cellooligomers. The alchemical approach of mutating hydroxyl groups into methyl groups was applied to aqueous cellotetraose, as a model for longer glucan chains. In the common synthesis route for $\mathrm{MC}$, glucan chains are heterogeneously 2-, 3-, and 6-O-methylated. Here, one of the middle residues in cellotetraose was individually methylated in either of the three positions, respectively. The free energy change associated with the mutation depends on in which position it occurs. The calculated $\Delta \Delta G_{s}$ was smallest for 3-O-methylation (2.3 \pm $\left.0.2 \mathrm{~kJ} \mathrm{~mol}^{-1}\right)$, followed 2-O-methylation $\left(3.6 \pm 0.2 \mathrm{~kJ} \mathrm{~mol}^{-1}\right)$, which both were considerably smaller than for 6-Omethylation $\left(14.6 \pm 0.2 \mathrm{~kJ} \mathrm{~mol}^{-1}\right)$. Note that this order should not be confused with reactivities, as the calculated energy reflects the change in solvation properties, which are consequences of the methylation, not the chemical reaction itself. In fact, experiments show that $\mathrm{O} 2$ is the one most prone to methylation in both glucose derivatives ${ }^{78,79}$ and in cellulose under homogenous ${ }^{14}$ reaction conditions, whereas the reactivities of $\mathrm{O} 2$ and $\mathrm{O} 6$ are similar under heterogeneous reaction conditions. ${ }^{80}$

The results presented here stand in sharp contrast to $\mathrm{Yu}$ et al. $^{24}$ who calculated the average $\Delta \Delta G_{\mathrm{s}}$ to $43 \mathrm{~kJ} \mathrm{~mol}^{-1}, 24 \mathrm{~kJ}$ $\mathrm{mol}^{-1}$, and $17 \mathrm{~kJ} \mathrm{~mol}^{-1}$, respectively, for 2-, 3-, and 6-Omethylation in cellononaose using an early version of the GROMOS carbohydrate force field. The result for C6 is similar to our result, but for $\mathrm{C} 2$ and $\mathrm{C} 3$, the value is larger and the ordering of the respective positions different than in the present work. The most likely explanation for this discrepancy is effects of poor convergence. While the previous result was based on five-ns simulations at room temperature, our results are based on considerably more data and also employed REMD, which has been shown before to be essential for satisfactory convergence of the conformational dynamics of carbohydrates. ${ }^{40,81}$ Moreover, we argue that the order O6 > $\mathrm{O} 2>\mathrm{O} 3$ is quite reasonable. Radial distribution functions (RDF) between hydroxyl protons (for the unsubstituted case) or methyl groups (for the methylated case), and oxygen atoms of water, for O2, O3, and O6, respectively, are shown in Figure 9. It is evident from the RDFs that the water structure around the methyl groups is very similar in all three positions. For the unsubstituted cellotetraose, on the other hand, there is clear difference visible in the first and second solvation peaks. Their respective heights follow the same order as the corresponding $\Delta \Delta G_{s}$. This points to a correlation between free energy of solvation and magnitude of perturbation of the water structure: the more hydrated the hydroxyl group, the larger the perturbation from methylation, which manifests in a larger $\Delta \Delta G_{\mathrm{s}}$.

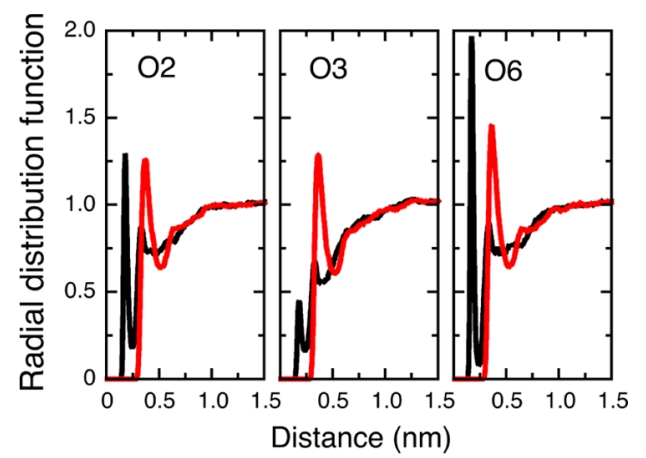

Figure 9. Radial distribution functions between hydroxyl proton (black) or methyl group (red) to oxygen atoms of water, for O2, O3, and $\mathrm{O} 6$ in the second glucose unit of cellotetraose, calculated from 5 ns of the simulations at $298 \mathrm{~K}$ (employing REMD).

Furthermore, we note that $\Delta \Delta G_{\mathrm{s}}$ exhibits only a very weak dependence on temperature, if any (Figure 10), for all three positions. Thus, the present calculations are not sufficient to explain the more complex temperature behavior of $\mathrm{MC}$ suspensions.

Effect on Flexibility. It is also of interest to investigate whether methylation affects the conformation of polysaccharides in solution, in part because that can affect the solubility. The large-scale conformation of polysaccharides is governed by the local conformations of the glycosidic linkages, which can be described using two torsion angles, $\phi$ and $\psi$. To that end, distributions of these torsion angles were calculated from the simulations of the methylated cellotetraose (Figure 11). The distributions show that it is only 3-O-methylation that affects the glycosidic linkage, and only the linkage that is the closest to the substitution point, $\phi_{2}$ and $\psi_{2}$ in the present case. Both $\phi_{2}$ and $\psi_{2}$ are shifted to higher torsion angles indicating a slightly larger twist between two consecutive units, and the distribution of $\psi_{2}$ is further broadened indicating slightly higher flexibility. However, these changes are quite small and lead to no significant deviation from an extended conformation.

Hydrogen bonding has been suggested to affect the conformation. A cellobiose unit in its most probable conformation can simultaneously form two trans-glycosidic hydrogen bonds between $\mathrm{O} 3 \mathrm{H} \cdots \mathrm{O}^{\prime}$ and $\mathrm{O} 6 \mathrm{H} \cdots \mathrm{O} 2 \mathrm{H}^{\prime}$. Methylation thus removes these hydrogen bonding possibilities, and this has been suggested to lead to increased flexibility. ${ }^{25}$ However, MD simulations showed that the $\phi / \psi$

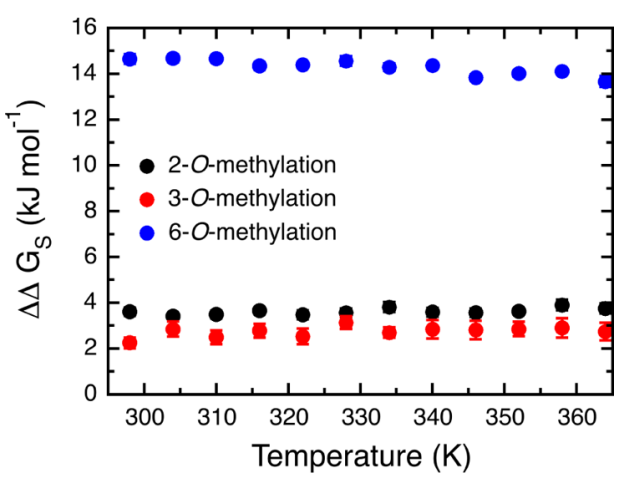

Figure 10. Change in solvation free energy upon methylation of the second glucose unit in cellotetraose in the $\mathrm{O} 2, \mathrm{O} 3$, and $\mathrm{O} 6$ positions, respectively, as a function of temperature. 

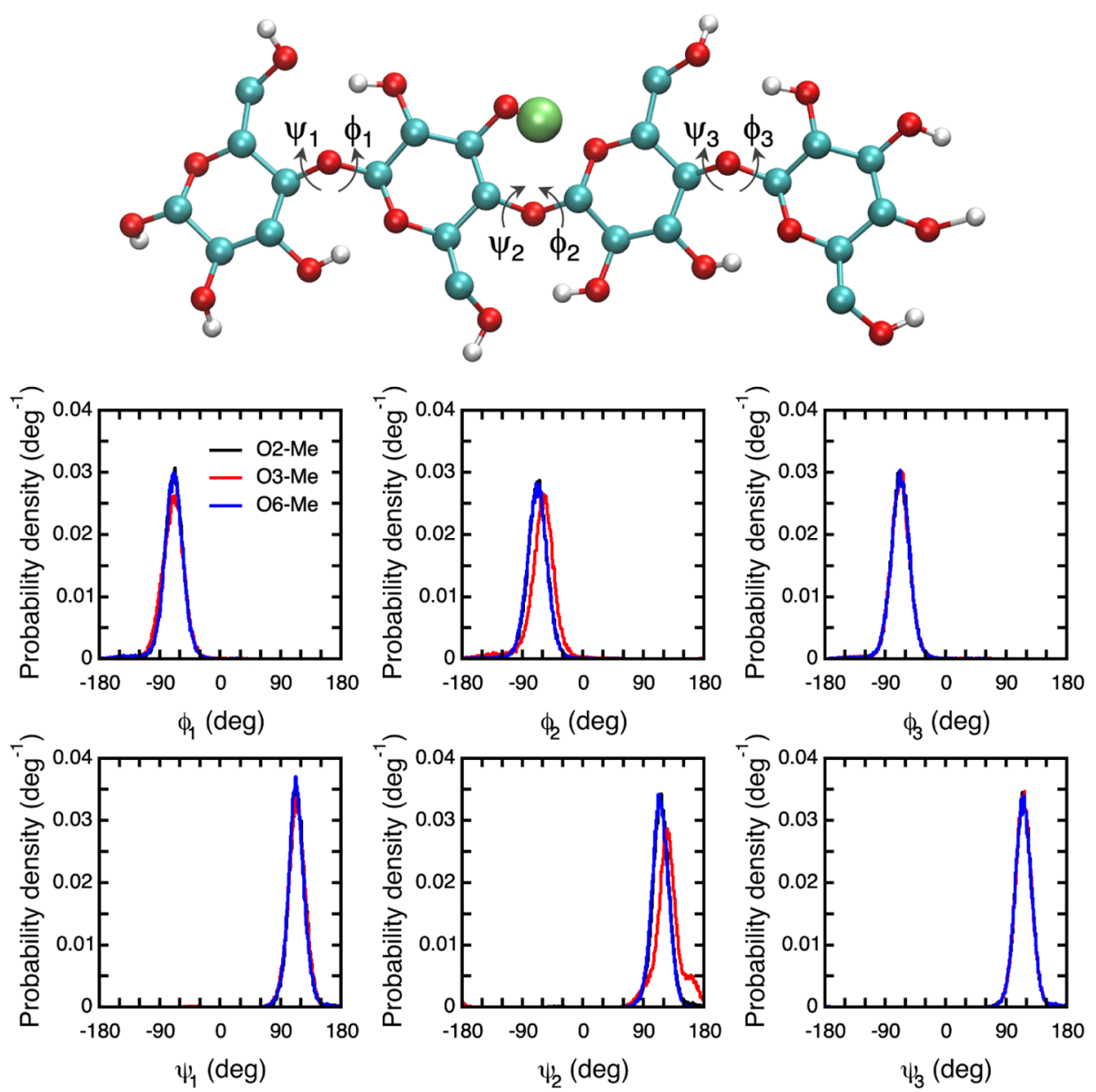

Figure 11. Cellotetraose, O3-methylated in the 2nd residue, and the torsion angles (IUPAC nomenclature) of the glycosidic linkages. The size of the methyl group has been exaggerated (top). Probability distributions of $\phi$ and $\psi$ for the glycosidic linkages in the methylated tetrasaccharides (bottom).

space for disaccharides of mannose and allose, where transglycosidic hydrogen bonding is suppressed due to having the hydroxyl groups in axial orientation, is almost identical to cellobiose. $^{82}$ This means that the difference observed from methylation at $\mathrm{O} 3$ probably is a consequence of increased steric interactions.

The observations presented herein agree with earlier simulations of methylated cellobiose in water using the same force field, ${ }^{21}$ which also noted an increase in $\phi$ and $\psi$ upon 3O-methylation. However, in a study of methylated cellononaose in water ${ }^{24}$ using the same force field, a slight decrease of both $\phi$ and $\psi$ was observed. Interestingly, it was also found in a more recent study employing the GLYCAM06 force field that blocks of successive $\mathrm{O} 3$ methylation resulted in a significant decrease in $\psi$, compared to a substitution pattern where every other unit was methylated. ${ }^{25}$ This indicates an effect from substitution pattern on conformational flexibility. It should be noted though that the latter simulations may not necessarily be well-converged. It is well known that conformations of saccharides, both hydroxymethyl rotations ${ }^{40}$ and glycosidic linkages, ${ }^{83}$ take a long time to converge to their equilibrium distributions in water at room temperature, unless methods to enhance the sampling are employed. This complicates the comparison between simulation studies and may account for the discrepancies.

\section{CONCLUSIONS}

The present study reports on both conformational and solvation properties of methylated mono- and tetrasaccharides from solution NMR and molecular dynamics simulations. The simulations show overall good agreement with experimental NMR coupling constants and derived populations relevant to the $\omega$ torsion that describes the orientation of the primary alcohol. It is found that 6-O-methylation affects $\omega$ only slightly, both as determined from NMR experiment and when compared among the MD simulations of the monosaccharides. The NMR experiment reveals the population preference of the $\theta$ torsion angle of $\beta$-D-Glcp6Me-OMe as $t>g^{+}>g^{-}$, captured also by the MD simulation, albeit with the trans state overestimated.

Calculated differences in hydration free energies between non-methylated and methylated molecules using two different methods-either by decoupling the solute-solvent interactions or by mutating the hydroxyl group into an O-methyl group using computational alchemy-yield internally consistent results. Moreover, when these methods are applied to the difference between methanol and DME, the calculated free energy difference is also consistent with experimental data obtained from Henry's law constants at infinite dilution, providing a general validation of both the method and the potential parameters. 
The computational alchemy approach was subsequently applied to methylated cellotetraose as a model for MC. It was found that methylation increases the hydration free energy by 2.3, 3.6, and $14.6 \mathrm{~kJ} \mathrm{~mol}^{-1}$ for 3-, 2-, and 6-O-methylation, respectively. These results stand in contrast to those previously reported, which highlights the need for applying both enhanced sampling methods and long simulations to obtain converged results for carbohydrates in solution.

The results presented herein have led to insights about the Karplus equations and their relationships to MD simulations, in particular the GROMOS 56 carbohydrate force field, and will serve as an important basis for simulation studies on more specialized topics related to $\mathrm{MC}$ and other methylated carbohydrates.

\section{ASSOCIATED CONTENT}

\section{SI Supporting Information}

The Supporting Information is available free of charge at https://pubs.acs.org/doi/10.1021/acs.jpcb.1c07293.

Description of the chemical synthesis of model compounds; ${ }^{1} \mathrm{H}$ and ${ }^{13} \mathrm{C}$ NMR spectra of monosaccharides; and plots of all Karplus-type equations (PDF)

\section{AUTHOR INFORMATION}

\section{Corresponding Authors}

Göran Widmalm - Department of Organic Chemistry, Arrhenius Laboratory, Stockholm University, SE-106 91 Stockholm, Sweden; (1) orcid.org/0000-0001-8303-4481; Email: goran.widmalm@su.se

Jakob Wohlert - Department of Fiber and Polymer Technology, School of Chemistry, Biotechnology and Health and Wallenberg Wood Science Center, KTH Royal Institute of Technology, SE-100 44 Stockholm, Sweden; (1) orcid.org/ 0000-0001-6732-2571; Email: jacke@kth.se

\section{Author}

Alessandro Ruda - Department of Organic Chemistry, Arrhenius Laboratory, Stockholm University, SE-106 91 Stockholm, Sweden

Complete contact information is available at:

https://pubs.acs.org/10.1021/acs.jpcb.1c07293

\section{Notes}

The authors declare no competing financial interest.

\section{ACKNOWLEDGMENTS}

This work was supported by grants from the Swedish Research Council (no. 2017-03703) and The Knut and Alice Wallenberg Foundation. Computations were enabled by resources provided by the Swedish National Infrastructure for Computing (SNIC) at PDC Center for High Performance Computing, KTH Royal Institute of Technology, partially funded by the Swedish Research Council through grant agreement no. 201805973. Dr A. S. Serianni, University of Notre Dame, is gratefully acknowledged for sharing computed data from ref 69.

\section{REFERENCES}

(1) Staudacher, E. Methylation - an uncommon modification of glycans. Biol. Chem. 2012, 393, 675-685.

(2) Martínez-Abad, A.; Berglund, J.; Toriz, G.; Gatenholm, P.; Henriksson, G.; Lindström, M.; Wohlert, J.; Vilaplana, F. Regular motifs in xylan modulate molecular flexibility and interactions with cellulose surfaces. Plant Physiol. 2017, 175, 1579-1592.

(3) Jackson, M.; Brennan, P. J. Polymethylated polysaccharides from Mycobacterium species revisited. J. Biol. Chem. 2009, 284, 19491953.

(4) Maranha, A.; Moynihan, P. J.; Miranda, V.; Correia Lourenço, E.; Nunes-Costa, D.; Fraga, J. S.; José Barbosa Pereira, P.; MacedoRibeiro, S.; Ventura, M. R.; Clarke, A. J.; Empadinhas, N. Octanoylation of early intermediates of mycobacterial methylglucose lipopolysaccharides. Sci. Rep. 2015, 5, 13610.

(5) Tuffal, G.; Albigot, R.; Rivière, M.; Puzo, G. Newly found 2-Nacetyl-2,6-dideoxy- $\beta$-glucopyranose containing methyl glucose polysaccharides in M.bovis BCG: revised structure of the mycobacterial methyl glucose lipopolysaccharides. Glycobiology 1998, 8, 675-684.

(6) De, P.; McNeil, M.; Xia, M.; Boot, C. M.; Hesser, D. C.; Denef, K.; Rithner, C.; Sours, T.; Dobos, K. M.; Hoft, D.; et al. Structural determinants in a glucose-containing lipopolysaccharide from Mycobacterium tuberculosis critical for inducing a subset of protective T cells. J. Biol. Chem. 2018, 293, 9706-9717.

(7) Patra, S.; Maity, K. K.; Bhunia, S. K.; Dey, B.; Das, D.; Mondal, S.; Bhunia, B.; Maiti, T. K.; Islam, S. S. Structural characterization of an immunoenhancing heteropolysaccharide from hot water extract of the fresh leaves of Catharanthus rosea. Carbohydr. Polym. 2010, 81, $584-591$.

(8) Anggara, K.; Zhu, Y.; Fittolani, G.; Yu, Y.; Tyrikos-Ergas, T.; Delbianco, M.; Rauschenbach, S.; Abb, S.; Seeberger, P. H.; Kern, K. Identifying the origin of local flexibility in a carbohydrate polymer. Proc. Natl. Acad. Sci. U.S.A. 2021, 118, No. e2102168118.

(9) Nasatto, P.; Pignon, F.; Silveira, J.; Duarte, M.; Noseda, M.; Rinaudo, M. Methylcellulose, a Cellulose Derivative with Original Physical Properties. Polymers 2015, 7, 777-803.

(10) Bergenstråhle, M.; Wohlert, J.; Himmel, M. E.; Brady, J. W. Simulation studies of the insolubility of cellulose. Carbohydr. Res. 2010, 345, 2060-2066.

(11) Lindman, B.; Medronho, B.; Alves, L.; Norgren, M.; Nordenskiöld, L. Hydrophobic interactions control the self-assembly of DNA and cellulose. Q. Rev. Biophys. 2021, 54, 1-22.

(12) Li, L.; Thangamathesvaran, P. M.; Yue, C. Y.; Tam, K. C.; Hu, X.; Lam, Y. C. Gel Network Structure of Methylcellulose in Water. Langmuir 2001, 17, 8062-8068.

(13) Fairclough, J. P. A.; Yu, H.; Kelly, O.; Ryan, A. J.; Sammler, R. L.; Radler, M. Interplay between Gelation and Phase Separation in Aqueous Solutions of Methylcellulose and Hydroxypropylmethylcellulose. Langmuir 2012, 28, 10551-10557.

(14) Nagel, M. C. V.; Koschella, A.; Voiges, K.; Mischnick, P.; Heinze, T. Homogeneous methylation of wood pulp cellulose dissolved in $\mathrm{LiOH} /$ urea/H2O. Eur. Polym. J. 2010, 46, 1726-1735.

(15) Widmalm, G. A perspective on the primary and threedimensional structures of carbohydrates. Carbohydr. Res. 2013, 378, 123-132.

(16) Shi, Q.; Yan, J.; Jiang, B.; Chi, X.; Wang, J.; Liang, X.; Ai, X. A general strategy for the structural determination of carbohydrates by multi-dimensional NMR spectroscopies. Carbohydr. Polym. 2021, 267, 118218

(17) Hadad, M. J.; Zhang, W.; Turney, T.; Sernau, L.; Wang, X.; Woods, R. J.; Incandela, A.; Surjancev, I.; Wang, A.; Yoon, M.-K.; et al. NMR Spin-Couplings in Saccharides: Relationships Between Structure, Conformation and the Magnitudes of $\mathrm{J}_{\mathrm{HH}}, \mathrm{J}_{\mathrm{CH}}$, and $\mathrm{J}_{\mathrm{CC}}$ Values. In NMR in Glycoscience and Glycotechnology; Kato, K., Peters, T., Eds.; Royal Society of Chemistry: London, 2017; pp 20-100.

(18) Guvench, O.; Greene, S. N.; Kamath, G.; Brady, J. W.; Venable, R. M.; Pastor, R. W.; MacKerell, A. D. Additive Empirical Force Field for Hexopyranose Monosaccharides. J. Comput. Chem. 2008, 29, $2543-2564$.

(19) Kirschner, K. N.; Yongye, A. B.; Tschampel, S. M.; GonzálezOuteiriño, J.; Daniels, C. R.; Foley, B. L.; Woods, R. J. GLYCAM06: A Generalizable Biomolecular Force Field. Carbohydrates. J. Comput. Chem. 2008, 29, 622-655. 
(20) Hansen, H. S.; Hünenberger, P. H. A Reoptimized GROMOS Force Field for Hexopyranose-Based Carbohydrates Accounting for the Relative Free Energies of Ring Conformers, Anomers, Epimers, Hydroxymethyl Rotamers, and Glycosidic Linkage Conformations. J. Comput. Chem. 2010, 32, 998-1032.

(21) Huang, W.; Dalal, I. S.; Larson, R. G. Analysis of Solvation and Gelation Behavior of Methylcellulose Using Atomistic Molecular Dynamics Simulations. J. Phys. Chem. B 2014, 118, 13992-14008.

(22) Huang, W.; Ramesh, R.; Jha, P. K.; Larson, R. G. A Systematic Coarse-Grained Model for Methylcellulose Polymers: Spontaneous Ring Formation at Elevated Temperature. Macromolecules 2016, 49, $1490-1503$.

(23) Ginzburg, V. V.; Sammler, R. L.; Huang, W.; Larson, R. G. Anisotropic Self-Assembly and Gelation in Aqueous Methylcellulose-Theory and Modeling. J. Polym. Sci., Part B: Polym. Phys. 2016, 54, 1624-1636.

(24) Yu, H.; Amann, M.; Hansson, T.; Köhler, J.; Wich, G.; van Gunsteren, W. F. Effect of methylation on the stability and solvation free energy of amylose and cellulose fragments: a molecular dynamics study. Carbohydr. Res. 2004, 339, 1697-1709.

(25) Yu, Y.; Tyrikos-Ergas, T.; Zhu, Y.; Fittolani, G.; Bordoni, V.; Singhal, A.; Fair, R. J.; Grafmüller, A.; Seeberger, P. H.; Delbianco, M. Systematic hydrogen-bond manipulation to establish polysaccharide structure-property correlations. Angew. Chem., Int. Ed. 2019, 58, 13127-13132.

(26) Pauli, G. F.; Chen, S.-N.; Lankin, D. C.; Bisson, J.; Case, R. J.; Chadwick, L. R.; Gödecke, T.; Inui, T.; Krunic, A.; Jaki, B. U.; et al. Essential Parameters for Structural Analysis and Dereplication by ${ }^{1} \mathrm{H}$ NMR Spectroscopy. J. Nat. Prod. 2014, 77, 1473-1487.

(27) Zangger, K.; Sterk, H. Homonuclear broadband-decoupled NMR spectra. J. Magn. Reson. 1997, 124, 486-489.

(28) Moutzouri, P.; Chen, Y.; Foroozandeh, M.; Kiraly, P.; Phillips, A. R.; Coombes, S. R.; Nilsson, M.; Morris, G. A. Ultraclean pure shift NMR. Chem. Commun. 2017, 53, 10188.

(29) Nishida, T.; Widmalm, G.; Sandor, P. Hadamard long-range proton-carbon coupling constant measurements with band-selective proton decoupling. Magn. Reson. Chem. 1995, 33, 596-599.

(30) Nishida, T.; Widmalm, G.; Sándor, P. Hadamard long-range proton-carbon coupling constant measurements with pulsed field gradients. Magn. Reson. Chem. 1996, 34, 377-382.

(31) Stott, K.; Keeler, J.; Van, Q. N.; Shaka, A. J. One-dimensional NOE experiments using pulsed field gradients. J. Magn. Reson. 1997, $125,302-324$.

(32) Garza-García, A.; Ponzanelli-Velásquez, G.; del Rio Portílla, F. Deconvolution and measurement of spin-spin splittings by modified J doubling in the frequency domain. J. Magn. Reson. 2001, 148, 214219.

(33) Stenutz, R.; Carmichael, I.; Widmalm, G.; Serianni, A. S. Hydroxymethyl Group Conformation in Saccharides: Structural Dependencies of ${ }^{2} \mathrm{~J}_{\mathrm{HH}},{ }^{3} \mathrm{~J}_{\mathrm{HH}}$ and ${ }^{1} \mathrm{~J}_{\mathrm{CH}}$ Spin-Spin Coupling Constants. J. Org. Chem. 2002, 67, 949-958.

(34) Thibaudeau, C.; Stenutz, R.; Hertz, B.; Klepach, T.; Zhao, S.; Wu, Q.; Carmichael, I.; Serianni, A. S. Correlated C-C and C-O Bond Conformations in Saccharide Hydroxymethyl Groups: Parametrization and Application of Redundant ${ }^{1} \mathrm{H}-{ }^{1} \mathrm{H},{ }^{13} \mathrm{C}-{ }^{1} \mathrm{H}$, and ${ }^{13} \mathrm{C}-{ }^{13} \mathrm{C}$ NMR J-Couplings. J. Am. Chem. Soc. 2004, 126, 15668-15685.

(35) Meredith, R. J.; Woods, R. J.; Carmichael, I.; Serianni, A. S. Reconciling MAAT and molecular dynamics models of linkage conformation in oligosaccharides. Phys. Chem. Chem. Phys. 2020, 22, 14454.

(36) Tvaroška, I.; Hrikovíni, M.; Petráková, E. An ettempts to derive a new Karplus-type equation of vicinal proton-carbon coupling constants for C-O-C-H segments of bonded atoms. Carbohydr. Res. 1989, 189, 359-362.

(37) Tvaroška, I.; Gajdoš, J. Angular dependence of vicinal carbonproton coupling constants for conformational studies of the hydroxymethyl group in carbohydrates. Carbohydr. Res. 1995, 271, $151-162$.
(38) Watson, A.; Simmermaker, C.; Aung, E.; Do, S.; Hackbusch, S.; Franz, A. H. NMR analysis and molecular dynamics conformation of $\alpha-1,6$-linear and $\alpha$-1,3-branched isomaltose oligomers as mimetics of $\alpha$-1,6-linked dextran. Carbohydr. Res. 2021, 503, 108296.

(39) Berendsen, H. J. C.; Grigera, J. R.; Straatsma, T. P. The Missing Term in Effective Pair Potentials. J. Phys. Chem. 1987, 91, 62696271.

(40) Angles d'Ortoli, T.; Sjöberg, N. A.; Vasiljeva, P.; Lindman, J.; Widmalm, G.; Bergenstråhle-Wohlert, M.; Wohlert, J. Temperature Dependence of Hydroxymethyl Group Rotamer Populations in Cellooligomers. J. Phys. Chem. B 2015, 119, 9559-9570.

(41) Malde, A. K.; Zuo, L.; Breeze, M.; Stroet, M.; Poger, D.; Nair, P. C.; Oostenbrink, C.; Mark, A. E. An Automated force field Topology Builder (ATB) and repository: version 1.0. J. Chem. Theory Comput. 2011, 7, 4026-4037.

(42) Schmid, N.; Eichenberger, A. P.; Choutko, A.; Riniker, S.; Winger, M.; Mark, A. E.; van Gunsteren, W. F. Definition and testing of the GROMOS force-field versions 54A7 and 54B7. Eur. Biophys. J. 2011, 40, 843.

(43) Abraham, M. J.; Murtola, T.; Schulz, R.; Páll, S.; Smith, J. C.; Hess, B.; Lindahl, E. GROMACS: High performance molecular simulations through multi-level parallelism from laptops to supercomputers. SoftwareX 2015, 1-2, 19-25.

(44) Darden, T.; York, D.; Pedersen, L. Partice Mesh Ewald: An N$\log (\mathrm{N})$ Method for Ewald Sums in Large Systems. J. Chem. Phys. 1993, 98, 10089-10092.

(45) Essmann, U.; Perera, L.; Berkowitz, M. L.; Darden, T.; Lee, H.; Pedersen, L. G. A Smooth Particle Mesh Ewald Method. J. Chem. Phys. 1995, 103, 8577-8593.

(46) Sugita, Y.; Okamoto, Y. Replica-Exchange Molecular Dynamics Method for Protein Folding. Chem. Phys. Lett. 1999, 314, 141-151.

(47) Bussi, G.; Donadio, D.; Parrinello, M. Canonocal Sampling Through Velocity Rescaling. J. Chem. Phys. 2007, 126, 014101.

(48) Parrinello, M.; Rahman, A. Polymorphic Transitions in Single Crystals: a New Molecular Dynamics Method. J. Appl. Phys. 1981, 52, 7182-7190.

(49) Goga, N.; Rzepiela, A. J.; de Vries, A. H.; Marrink, S. J.; Berendsen, H. J. C. Efficient algorithms for Langevin and DPD dynamics. J. Chem. Theory Comput. 2012, 8, 3637-3649.

(50) Straatsma, T. P.; McCammon, J. A. Computational alchemy. Annu. Rev. Phys. Chem. 1992, 43, 407-435.

(51) Bennett, C. H. Efficient estimation of free energy differences from Monte Carlo data. J. Comput. Phys. 1976, 22, 245-268.

(52) Chen, P.; Lo Re, G.; Berglund, L. A.; Wohlert, J. Surface modification effects on nanocellulose - molecular dynamics simulations using umbrella sampling and computational alchemy. J. Mater. Chem. A 2020, 8, 23617.

(53) Tani, S.; Sawadi, S.; Kojima, M.; Akai, S.; Sato, K.-i. A novel method for regioselective ring-opening reduction of 4,6-O-benzylidene hexopyranoside derivatives using $\mathrm{CoCl} 2$ and $\mathrm{BH} 3 \cdot \mathrm{THF}$. Tetrahedron Lett. 2007, 48, 3103-3104.

(54) Santra, A.; Ghosh, T.; Misra, A. K. Removal of benzylidene acetal and benzyl ether in carbohydrate derivatives using triethylsilane and $\mathrm{Pd} / \mathrm{C}$. Beilstein J. Org. Chem. 2013, 9, 74-78.

(55) Timell, T. E.; Enterman, W.; Spencer, F.; Soltes, E. J. The acid hydrolysis of glycosides. Can. J. Chem. 1965, 43, 2296-2305.

(56) Nishida, Y.; Hori, H.; Ohrui, H.; Meguro, H. ${ }^{1} \mathrm{H}$ NMR analyses of rotameric distribution of C5-C6 bonds of D-glucopyranoses in solution. J. Carbohydr. Chem. 1988, 7, 239-250.

(57) Bock, K.; Duus, J. Ø. A conformational study of hydroxymethyl groups in carbohydrates investigated by ${ }^{1} \mathrm{H}$ NMR spectroscopy. J. Carbohydr. Chem. 1994, 13, 513-543.

(58) Tvaroška, I.; Taravel, F. R.; Utille, J. P.; Carver, J. P. Quantum mechanical and NMR spectroscopy studies on the conformations of the hydroxymethyl and methoxymethyl groups in aldohexosides. Carbohydr. Res. 2002, 337, 353-367.

(59) Salam, A.; Deleuze, M. S. High-level theoretical study of the conformational equilibrium of n-pentane. J. Chem. Phys. 2002, 116, 1296. 
(60) Dharuman, S.; Amarasekara, H.; Crich, D. Interplay of protecting groups and side chain conformation in glycopyranosides. Modulation of the influence of remote substituents on glycosylation? J. Org. Chem. 2018, 83, 10334-10351.

(61) Hassel, O.; Ottar, B.; Roald, B.; Linnasalmi, A.; Laukkanen, P. The structure of molecules containing cyclohexane or pyranose rings. Acta Chem. Scand. 1947, 1, 929-943.

(62) Neuhaus, D.; Wagner, G.; Vašák, M.; Kägi, J. H. R.; Wüthrich, $\mathrm{K}$. Systematic application of high-resolution, phase-sensitive twodimensional H-NMR techniques for the identification of the aminoacid-proton spin systems in proteins Rabbit metallothionein-2. Eur. J. Biochem. 1985, 151, 257-273.

(63) Podlasek, C. A.; Wu, J.; Stripe, W. A.; Bondo, P. B.; Serianni, A. S. $\left[{ }^{13} \mathrm{C}\right]$-enriched methyl aldopyranosides: Structural interpretations ${ }^{13} \mathrm{C}-{ }^{1} \mathrm{H}$ spin coupling constants and ${ }^{1} \mathrm{H}$ chemical shifts. J. Am. Chem. Soc. 2002, 117, 8635-8644.

(64) Pendrill, R.; Säwén, E.; Widmalm, G. Conformation and Dynamics at a Flexible Glycosidic Linkage Revealed by NMR Spectroscopy and Molecular Dynamics Simulations: Analysis of $\beta$-LFucp- $(1 \rightarrow 6)-\alpha$-D-Glcp-OMe in Water Solution. J. Phys. Chem. B 2013, 117, 14709-14722.

(65) Amarasekara, H.; Dharuman, S.; Kato, T.; Crich, D. Synthesis of Conformationally-Locked cis- and trans-Bicyclo[4.4.0] Mono-, Di-, and Trioxadecane Modifications of Galacto- and Glucopyranose; Experimental Limiting 3JH,H Coupling Constants for the Estimation of Carbohydrate Side Chain Populations and Beyon. J. Org. Chem. 2018, 83, 881-897.

(66) Li, W.; Battistel, M. D.; Reeves, H.; Oh, L.; Yu, H.; Chen, X.; Wang, L.-P.; Freedberg, D. I. A combined NMR, MD and DFT conformational analysis of 9-O-acetyl sialic acid-containing GM3 ganglioside glycan and its 9-N-acetyl mimic. Glycobiology 2020, 30, $787-801$.

(67) Toukach, F. V.; Ananikov, V. P. Recent advances in computational predictions of NMR parameters for the structure elucidation of carbohydrates: methods and limitations. Chem. Soc. Rev. 2013, 42, 8376

(68) Odelius, M.; Laaksonen, A.; Widmalm, G. A model glycosidic linkage: An ab initio geometry optimization study of 2-cyclohexoxytetrahydropyran. J. Phys. Chem. 1995, 99, 12686-12692.

(69) Zhao, H.; Carmichael, I.; Serianni, A. S. Oligosaccharide transglycoside ${ }^{3} \mathrm{~J}_{\text {COCC }}$ Karplus curves are not equivalent: Effect of internal electronegative substituents. J. Org. Chem. 2008, 73, 3255-3257.

(70) Shen, T.; Langan, P.; French, A. D.; Johnson, G. P.; Gnanakaran, S. Conformational Flexibility of Soluble Cellulose Oligomers: Chain Length and Temperature Dependence. J. Am. Chem. Soc. 2009, 131, 14786-14794.

(71) Jasra, R. V.; Ahluwalia, J. C. Enthalpies of solution, partial molal heat capacities and apparent molal volumes of sugars and polyols in water. J. Solution Chem. 1982, 11, 325-338.

(72) Klimovich, P. V.; Mobley, D. L. Predicting hydration free energies using all-atom molecular dynamics simulations and multiple starting conformations. J. Comput.-Aided Mol. Des. 2010, 24, 307316.

(73) López, C. A.; Rzepiela, A. J.; de Vries, A. H.; Dijkhuizen, L.; Hünenberger, P. H.; Marrink, S. J. Martini coarse-grained force field: extension to carbohydrates. J. Chem. Theory Comput. 2009, 5, 31953210.

(74) Oja, V.; Suuberg, E. M. Vapor Pressures and Enthalpies of Sublimation of D-glucose, D-xylose, Cellobiose, and Levoglucosan. J. Chem. Eng. Data 1999, 44, 26-29.

(75) Geballe, M. T.; Skillman, A. G.; Nicholls, A.; Guthrie, J. P.; Taylor, P. J. The SAMPL2 blind prediction challenge: introduction and overview. J. Comput.-Aided Mol. Des. 2010, 24, 259-279.

(76) Jämbeck, J. P. M.; Mocci, F.; Lyubartsev, A. P.; Laaksonen, A. Partial atomic charges and their impact on the free energy of solvation. J. Comput. Chem. 2013, 34, 187-197.

(77) Hawkins, G. D.; Cramer, C. J.; Truhlar, D. G. Universal quantum mechanical model for solvation free energies based on gasphase geometries. J. Phys. Chem. B 1998, 102, 3257-3271.
(78) Croon, I.; Fernö, O.; Fex, H.; Högberg, B.; Kneip, P.; Palmstierna, H. Partial methylation of some glucose derivatives. Acta Chem. Scand. 1959, 13, 1235-1238.

(79) Lee, C. K.; Kim, E. J.; Jun, J. H. Determination of relative reactivities of free hydroxyl groups in cyclodextrin, amylose, and cellulose by reductive-cleavage method. Bull. Korean Chem. Soc. 1999, 20, 1153-1158.

(80) Takahashi, S.-I.; Fujimoto, T.; Barua, B. M.; Miyamoto, T.; Inagaki, $\mathrm{H} .{ }^{13} \mathrm{C}$ NMR spectral studies on the distribution of substituents in some cellulose derivatives. J. Polym. Sci., Part A: Polym. Chem. 1986, 24, 2981-2993.

(81) Berglund, J.; Angles d'Ortoli, T.; Vilaplana, F.; Widmalm, G.; Bergenstråhle-Wohlert, M.; Lawoko, M.; Henriksson, G.; Lindström, M.; Wohlert, J. A molecular dynamics study of the effect of glycosidic linkage type in the hemicellulose backbone on the molecular chain flexibility. Plant J. 2016, 88, 56-70.

(82) Wang, D.; Ámundadóttir, M. L.; van Gunsteren, W. F.; Hünenberger, P. H. Intramolecular hydrogen-bonding in aqueous carbohydrates as a cause or consequence of conformational preferences: a molecular dynamics study of cellobiose stereoisomers. Eur. Biophys. J. 2013, 42, 521-537.

(83) Perić-Hassler, L.; Hansen, H. S.; Baron, R.; Hünenberger, P. H. Conformational properties of glucose-based disaccharides investigated using molecular dynamics simulations with local elevation umbrella sampling. Carbohydr. Res. 2010, 345, 1781-1801. 